\title{
Optimal Management of Wind Intermittency in Constrained Electrical Network
}

\author{
Phuc Diem Nguyen Ngoc', Thi Thu Ha Pham², \\ Seddik Bacha ${ }^{1}$ and Daniel Roye ${ }^{1}$ \\ ${ }^{1}$ Grenoble Electrical Engineering Laboratory (G2ELAB), Saint Martin d'Hères \\ ${ }^{2}$ Projects \& Engineering Center (PEC) - Schneider Electric
}

France

\section{Introduction}

Wind electricity has known a spectacular increase since 1990, essentially due to governments' voluntarist policy. At present, this renewable energy is considered as the best economic profitability.

The success is accompanied by difficulties in short and medium terms and deep questionings in long term. Thus, coupling problem between wind generator and network perturbation, usually resulted by untimely decoupling, has to be studied. In medium term, the question will be around the general ancillary services problem such as voltage and frequency regulation. In long term, numerous questionings concerning the network capacity of wind power integration (e.g.: in Germany, 50 GW is planned by 2020) and the unsatisfying current premier reserves will be purposed. Therefore, new production infrastructures have to be built, especially with improved management plan which will link these new productions to stocks and load pilot.

Moreover, because of the continuously increasing penetration rate of wind power in power system, the management of wind power intermittency become more and more important.

In fact, network driver will meet a serial of difficulties that cannot be solved without actions directly on the flux of wind energy or indirectly by economical incitements (penalty/bonus) to wind producers.

An interesting schema for the wind energy management can be a coupling of wind generators and storages. Naturally, there are multiple varieties of wind generator and storage systems.

However, for the power level that can influence the grid, the most adapted systems of storage is turbine/pump ones.

In order to optimize the operation of wind and storage system, particular attention in existent research is given to maximizing economic benefit. Such an economical approach, suitable in the short-time frame for encouraging the wind development, assesses the wind intermittency as a technical-economic problem with network operating limit conditions. With large-scale of wind integration, the intermittency will have great impact on power system operation (fluctuations, stability, reserve capacity...). Network needs to apply more and more constraints on power quality delivery by wind system. In this context, the current 
work considers optimal operation of wind storage system as an optimization problem that deals with primary sources, storage capacity as well as demand. The main objective is to meet grid requirements in term of limiting the fluctuations and providing possible ancillary services. The intermittency management will be assessed into two steps: anticipation phase and reactivity phase. The first one, which will generally be done at Month-1, Week-1 or Day1 , consists in using forecast information (weather, network demand ...) to define the optimal operation schedule for wind - storage system. On real time operation, the system has to deal with possible vagaries and take the right adjustment control with actual capacity. The problem is complex with numerous discrete control variables and continuous ones. A mixed-integer linear programming (MILP) is used to efficiency solve the problem. An example is given to illustrate the proposed method. Results indicate that wind power with storage can meet the network requirements while best ensure its profits. Results also show that the proposed optimal operation strategy which limits considerably the fluctuations on power system will facilitate the integration of more wind power.

In this chapter, we deal with a wind system combined with a hydraulic storage (we name the system $\mathrm{W}+\mathrm{S}$ since now) where the input is the network demand power and the output is the provided wind power. This system has to response to the management requirements in taking into account the wind vagaries, the storage and de-storage capacity, the energetic cost of the flux transfer and highlighting economical efficiency.

\section{Introduction of corrective measures in order to face the intermittencies of wind energy}

Because of the fluctuations of wind energy, some corrective measures have been proposed to face the intermittencies.

- The choice of location for a wind power plant building

The choice of an optimal geographic location is one of the first criteria to be considered and analyzed in order to plan a significantly and stabilized production. Many geographic areas seem to be appropriate to the wind energy development: a uniform wind speed with few or no weather anomalies (storms and cyclones) guarantees a controlled production of energy.

For example, in France, the priority fields of wind energy development are determined by the following parameters:

- A high wind potential with three distinct wind patterns: north, west, south;

- The possibility to be connected to a national electrical network;

- The preservation of the land-use sites, that is to say, the guarantee of a low impact on landscape, environment, fauna, historic edifices and all other protected areas.

- $\quad$ Avoid proximity with military areas, airports, radar detections...

The priority regions for the wind energy development are (in France) Lorraine, Bretagne, Languedoc-Roussillon, Picardie, Champagne-Ardenne, Rhône-Alpes, Midi Pyrénées,...

- The improvement of the wind forecast accuracy (speed and direction)

Forecasting is a main factor giving the entry parameters of all the operational decisions related to the operation of the electrical systems in general, of the wind energy plants in particular. However, due to the continuous variation of the weather conditions, the wind speed forecast accuracy and to a lesser extent wind direction, is a main topic.

- $\quad$ Energy storage 
Energy storage is the key of all kind of integration of intermittency primary sources. Nevertheless, all the existing mature technologies are little or no adapted to the wind energy power scales (MW). Except for the three following ones:

- $\quad$ Big sized hydraulics or gravity-fed systems in general;

- Compressed air;

- Flywheels;

Each system is characterized by its power or its mass or energy volume, its efficiency and its cost; these parameters will be relevant ones for the choice of a technology than another.

And in this party, the use of wind power combined with storage means (mainly, pumped hydro storage system) is often proposed and chosen to limit the impact of the variability of wind power [SOM-03], [ANA-07].

\section{Problem description of operation of a wind power plant with an hydraulic storage within the electrical network}

3.1 An economic problem (old policy: only economic constraints taken into account) Beforehand, the energy policies emphasized the wind energy producers by introducing advantages on their produced energy purchase price and by neglecting the ancillary services criteria for this kind of energy. Indeed, the producers supplied energy without being concerned by:

- Voltage regulation;

- Frequency regulation and power regulation required by the grid;

- Adaptation of supplied energy in case of variable situations (dramatic wind speed fluctuations or network voltage drop).

With the growth of renewable energies in general and that of wind energy particularly, these advantages gradually decreased:

- The evolution of energy policy: subventions dedicated to renewable energies decrease;

- In prospect: increase of participation rate of renewable energies in the electrical network (20\% attempted in 2020);

- Increasing of imposed technical constraints.

Thus, optimization of $(\mathrm{W}+\mathrm{S})$ system operation is needed in order to better integrate the wind energy into the electrical system according to the new requirements of the grid.

\subsection{A technical-economic problem (real time or reactive management)}

Wind power plant management is the adaptation to the wind intermittencies in order to satisfy the electrical network requests. This is a global exercise where all elements must be carefully analyzed. Then, study of sources (location, weather and installed capacity), the prevision of the operation mode (seasonal forecasts, month, week, day and hour) and on the real time, optimal driving strategy must be considered.

Management of wind energy intermittencies can be separated in two phases: anticipation phase based on forecasting data (static management) and reactive phase on the real time (dynamic management).

- Anticipation management

Concerning this kind of management, the optimal operate diagram of a day is established thanks to previous day data. The drawback is that the performances depend on the accuracy of forecast data. The difference between the forecast data and the real data can generate 
technical errors and economic losses. To overcome this problem, a real time management can be proposed and anticipation plan for the optimal operation of system will be forecasted for tomorrow.

- Real time or reactive management

The aim is to obtain adapted optimal operate strategy and dynamic on the real time in case of unpredictable variations concerning wind speed or required grid power for example. The method is based on a continuous daily update as soon as entry data are not conformed to expected ones. As a result, a new optimal operate strategy is determined.

Thanks to the combination of the two management phases, the wind energy system with a hydraulic storage $(\mathrm{W}+\mathrm{S})$ is fully controlled. First, the forecast data is used. Then, they are compared to the real ones and the deviations, if there is one, is adapted in order to obtain a new optimal operate plan.

\section{Problem characterization}

\subsection{W+S system characterization}

The energy flux of the $\mathrm{W}+\mathrm{S}$ system is presented as the following figure. This system principal characterization is discussed in the next paragraphs of this part.

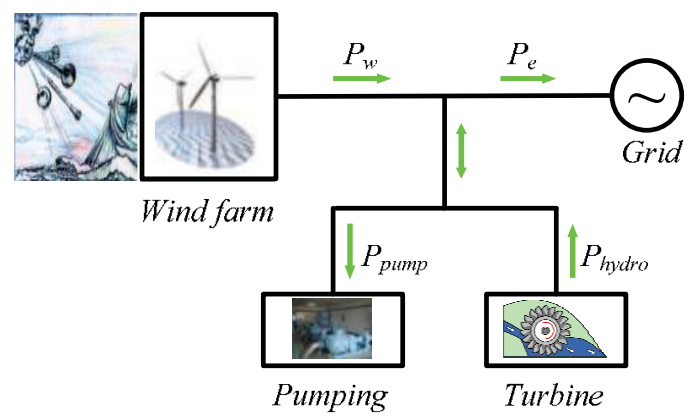

Fig. 1. Connection of the $\mathrm{W}+\mathrm{S}$ system to electric grids

\section{a. Continuous, discreet and intermittent nature}

- The wind power is an intermittent source

The variability of wind energy is due to the intermittent nature of wind and the process of converting wind energy into electrical energy.

The wind speed is constantly changing. This is a climatic phenomenon, which depends on several variables that are very difficult to predict with accuracy. Normally we use statistical tools to describe this phenomenon: the variation of wind is given by (1) using a Weibull distribution function and is illustrated in Figure 5. The statistical model is characterized by the scale factor $\mathrm{C}(\mathrm{m} / \mathrm{s})$ and the shape factor $\mathrm{k}$ (dimensionless).

$$
f(V)=\left(\frac{k}{C}\right) \cdot\left(\frac{V}{C}\right)^{k-1} \cdot \exp \left[-\left(\frac{V}{C}\right)\right]
$$

The $\mathrm{C}$ and $\mathrm{k}$ factors are estimated by using historical data of wind on the site considered for a long period. A description of wind conditions at many sites in Europe shows that in 
general, the value of $\mathrm{C}$ factor is between 2 and 8 and the $\mathrm{k}$ factor takes a value between 1.5 and 2, [BUR-01], [GAR-06], [GEN-05], [DWIA].

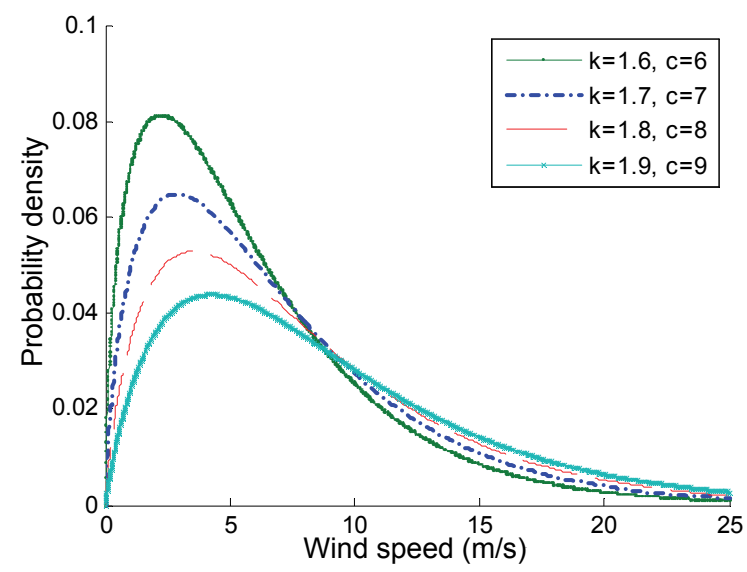

Fig. 2. Probability density

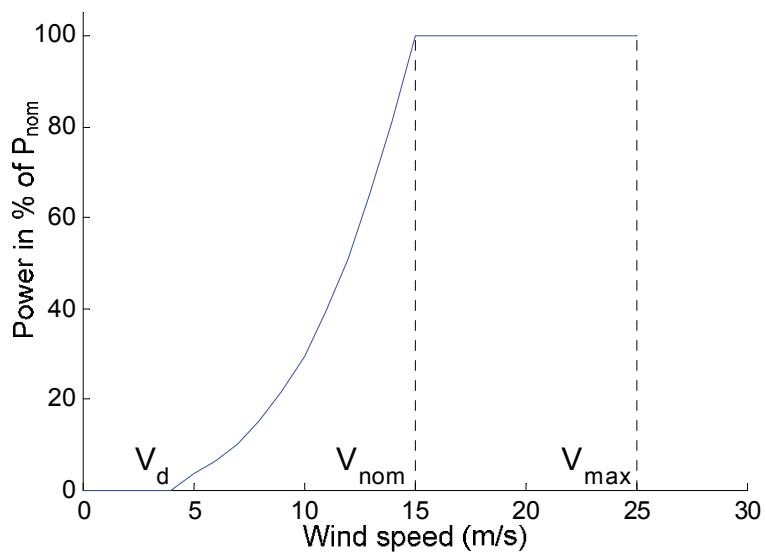

Fig. 3. Characteristic of the wind power according to the wind

In the wind turbines, electricity generation is directly related to the wind speed. The turbines convert wind energy into mechanical energy, which is then used by the electrical generator. The conversion process of a wind turbine is described by a power curve given by Betz expression:

$$
P=\frac{1}{2} \cdot C_{p} \cdot \rho \cdot \pi \cdot\left(\frac{D}{2}\right)^{2} \cdot V^{3}
$$


Where:

$\rho$ : density-dependent temperature

$\mathrm{P}$ : power generated by wind turbine

Cp: drag coefficient of power (specific to the wind farm)

$\mathrm{V}$ : wind speed

D: diameter of the blades

This expression is quite similar for different manufacturers and turbine types. The power is null if the wind speed is less than a starting speed (cut - in speed) ( $\mathrm{Vd}=2$ to $4 \mathrm{~m} / \mathrm{s}$ ), this power is also proportional to the wind speed rise between cut - in speed and the rated speed (about Vnom $=12$ to $16 \mathrm{~m} / \mathrm{s}$ ). At the rate speed the power is near its nominal value. Power is constant between the rated speed and cut - out speed (Vmax $=25$ to $30 \mathrm{~m} / \mathrm{s}$ ). Beyond the cut-off speed, the turbine is stopped for safety reasons.

By observing Figure 5 we see that the winds are more frequently at low and average speed than at strong velocity. Otherwise the (2) shows that the average wind power supplied by the turbine varies strongly with the cube of the average wind speed. Thus, a doubling of wind speed corresponds to an increase in its capacity energy $2^{\wedge} 3=8$ times.

Consequently, the variability of the wind and the process of energy conversion makes the wind generation an intermittent nature.

- The electric grid is considered as an intermittent source

The electric grid is a complex multi-actor system consisting of many uncertain factors like technical, human and natural factors. The uncertainty is present at several levels.

- Stochastic variation of demands (usually considered as the prediction error) has important effects on anticipating and on managing the real-time system. It is due to some related climates and consumer behaviours.

- Several types of uncertainty exist in electricity generation where the generating units cannot reach their production plans or where the production unit cannot start as expected or is stopped suddenly by natural or technical causes.

- Operation limits of the transportation and distribution systems have to be taken into account. The risk of disruption is high if one of these limits is violated, usually when the capacity of power transmission exceeds its limit or there are some technical restrictions on the use of lines. We called them congestion problems. They are unpredictable and normally occur following any incidents (errors of operations) or external aggressions (a tree branch falling on a line, overload, lightning or discharge on some lines...).

The combination of these uncertainties and the physic nature of the system, in plus with the difficulty of predicting the behavior of all factors increase the uncertainty on the system. Therefore the electric grid is considered as an intermittent source.

- Hydraulic storage system is a cumulative resource

In this storage system, water is stored in high basin in the form of potential energy. It is removed from storage into turbines to produce electricity when needed. Providing hydraulic pumping increases the storage energy while the discharge by the turbine reduces the volume of the basin. It is the characteristic of "storability" which leads us to consider not only the operation flexibility but also gives us un opportunity to produce energy at better valuated times. Thus, the main characteristic quantities of the storage system are:

- $\quad$ storage volume (in m3) and storage capacity (in watt-hours (Wh));

- different altitude between the two basins (upper and lower) (m);

- installed power and performance of hydroelectric turbines and pumping station. 
The storage state at any time is determined by the accumulation of volume available in the past and the provided and discharged volume at the time.

- Turbine and pump are the two alternate functions

The storage system, which operates with two closed basins, is considered as a closed circuit. In case of overproduction wind, water can be pumped into the upper to accumulate potential energy. The hydroelectric turbines use this water to produce electricity during high load demand. Therefore, both turbine and pumping are alternated functions. Moreover, the $\mathrm{W}+\mathrm{S}$ arms to maximize the value of wind energy. The hydroelectric storage plays the supported role. It is a non-permanent status (discrete). It is also important to note that for economic reasons, it is undesirable or even impossible to run two functions simultaneously, especially in the case where the system has only one forced operating system - type II.

b. Dynamics

The $\mathrm{W}+\mathrm{S}$ is a dynamic system. The time horizon considered for the $\mathrm{W}+\mathrm{S}$ system can be viewed at different time scales where the amplitude variation has not same values.

First, wind generation is intermittent but it sometimes shows a certain periodicity. In different seasons, we see that wind generation is more favourable in winter in the Nordic countries with a low pressure weather, or better in summer in the Mediterranean region thanks to the summer breezes [GAR-06], [PET-97].

The annual consumption of the electrical system also has a regular trend and is periodic. The power consumption increases year-by-year following the country development. The growth rate depends on development degree: low in industrialized countries and very strong in developing countries. In a year, season-by-season, energy demand is much higher in winter than in summer in cold countries and inverted trend in hot countries [GAR-06], [PET-97].

A example of annual win energy statistic is given in the following figures. Figure 7 gives potential wind energy between 2003 and 2008 on a site in Montpellier (southern France). Figure 8 shows of the monthly power consumption in France between 2003 and 2008.

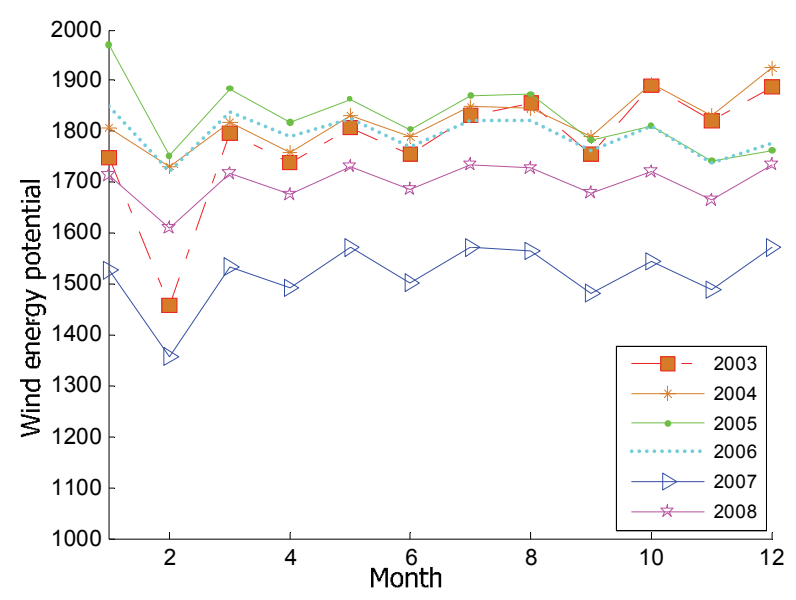

Fig. 4. Potential wind energy 


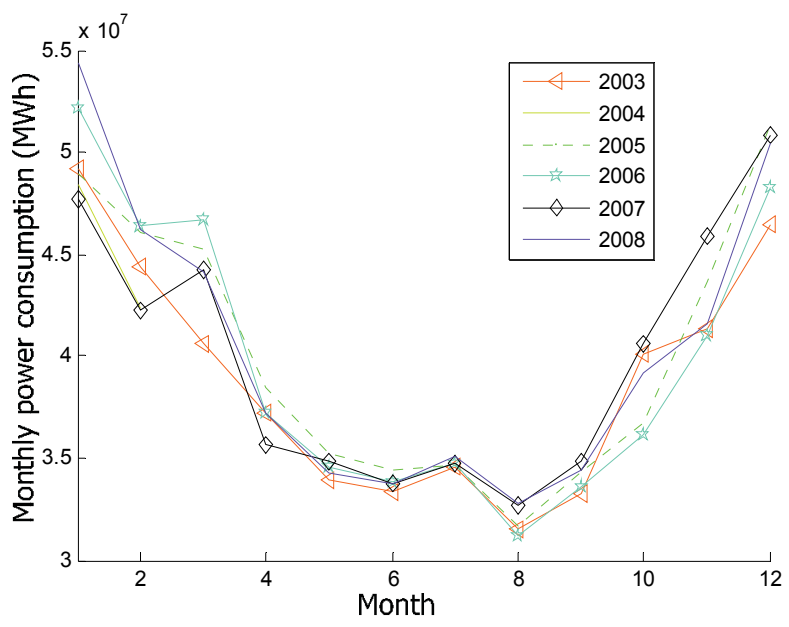

Fig. 5. Monthly power consumption

Thus, at this time scale, the forecast is based on the past history and on the modeling of climate effects or others recurring effects (festivals, big events ...).

We also note that diurnal cycles are mainly due to the effect of temperature for both wind generation and power consumption.

In reduced time scales (order of a minute) it is difficult to predict exactly the average wind speed and its level of fluctuation. Consumption also fluctuates unpredictably for the reasons cited in the above paragraph. However, we note that changes in short-term consumption are rather "continuous" or "progressive".

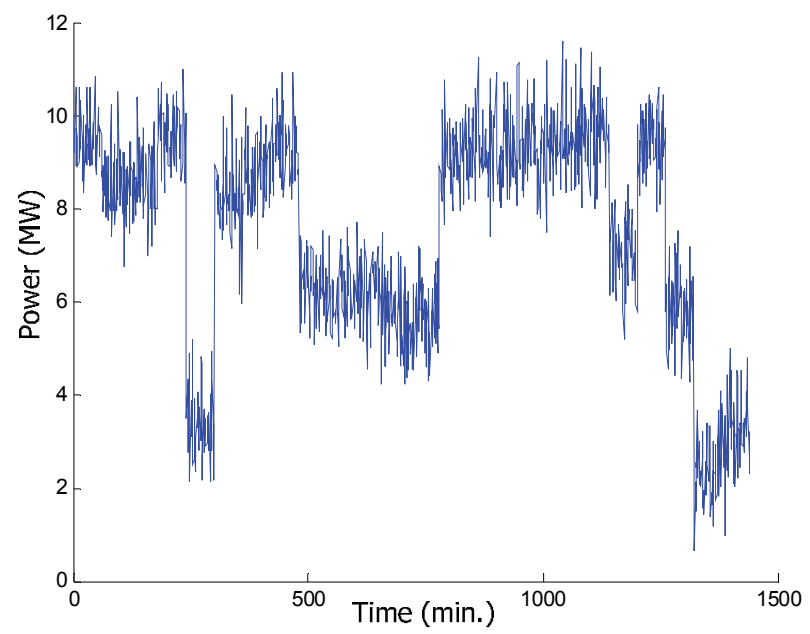

Fig. 6. Wind generation 


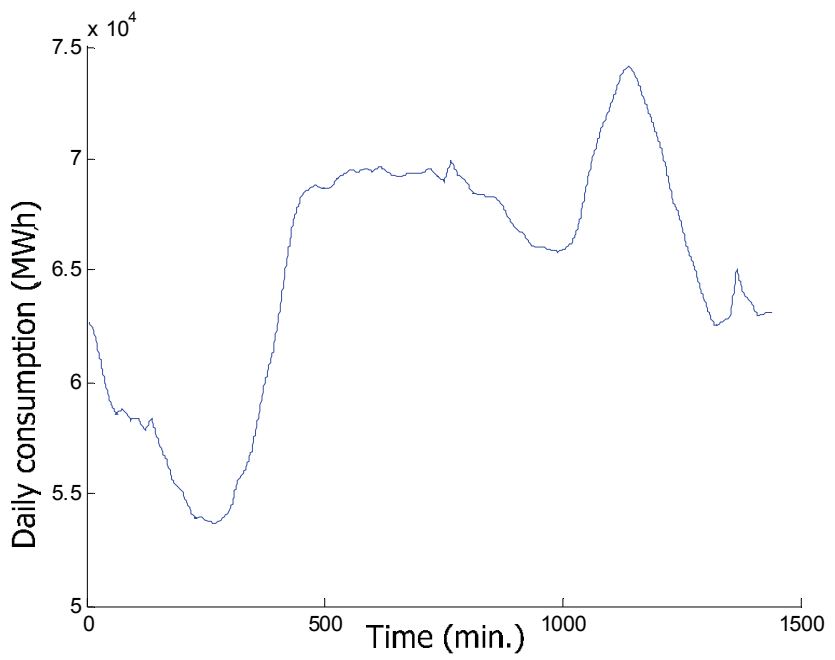

Fig. 7. Daily consumption

The following analyses show us some observations:

- in medium term (week, month, season, year): variability is rather slow and periodic;

- $\quad$ in short term (day): the variations are large and associated with large uncertainties;

- $\quad$ in very short term (some minutes): fluctuations are very fast with amplitudes rather unpredictable.

Every time horizon type of variability and its impact on the operation of different system. Therefore, it is important to take into account this dynamic characteristic of the $\mathrm{W}+\mathrm{S}$ in the developed approaches which arms to optimize the intermittency management.

\section{c. System benefits}

The economic and financial needs have to meet the profitability of the system. Because, despite technological and techniques progress in recent decades, the economic incitements and the trend of wind energy integration into electrical system, the price of energy produced by this source is still higher than conventional sources. The economic criteria are still among the top regardless of adopted management strategy.

\subsection{Towards an optimized management}

The presented characteristics of the $\mathrm{W}+\mathrm{S}$ system have highlighted a need to develop a optimized and appropriate management approach. It arms to determine the schedules of on- off operation and the quantity of energy of all components in the system (wind - hydro pumping), which meets the technical and / or economic criteria. The coordination of components operation in the system should be part of an overall vision and be composed of several levels of control for the different time scales.

How do we define an optimal strategy of operation management? The answer depends on the conditions of wind integration in the electrical system.

Nowaday, the development of wind power in several European countries (Germany, Spain, Denmark...) is explained by the support policy adopted by its governments. These include not only regulation policy (required purchase, quotas) applied to electricity distributors but 
also an attractive remuneration per $\mathrm{kWh}$ generated by wind power (investment subsidies, guaranteed purchase price). This policy, known mechanism of integration, is obviously intended to increase wind energy generation to maximize its profitability. Fluctuations are less disadvantageous and are even negligible for wind power producers. The operational and financial responsibility of the intermittent management refers to different actors of the electrical system. The quality of results and the effectiveness of this policy are proven by the substantial growing of wind turbines installation over worldwide during recent years. Thus, for wind energy producers, the best management approach arms to maximize the profit from selling wind generation by maximizing win energy penetration into the grid, at the best price [HAL-01], [GER-02], [CAS-03], [MAG-03], [CAS-04a], [CAS-04b], [CAS-04c], [KAL-07], [BEN-08], [NGU-09], [EWE-09].

A management strategy is supported when wind generation is still a marginal source among available sources. The impact caused by the intermittent operation of the system is less visible and often merged by the consumption vagary. So if we investigate for medium term, wind power should continue to grow. The management of vagary involved in wind energy would be of not only a technical challenge - because the dependability of the system depends, but also an economic issue - for the management of the vagary has a cost (disturbances need increase operating margins...). The question supposed to the electrical system is that will be the acceptable level of fluctuation? Should we accept these risks or consider eventually wind power as an independent producer in order to meet specific technical constraints and electricity market rules. The management of the wind system in upcoming years would inevitably focus on the answer to this question.

We focus on this context and are going to set up an optimized management approach of the $\mathrm{W}+\mathrm{S}$ system.

\section{Optimized management method for W+S systems}

\subsection{Architect of the management system}

To initialize an optimized management method for W+S systems, we base on two levels of control: the anticipation of the operation system and the dynamic and responsive management in real time.

\section{a. Anticipation of the operation system}

In general, the anticipation is the most important step in the operation system. The objectives here are to define the plan of operation of all components in the system in subjecting to meet all the technical constraints in order to achieve the target during a period. Therefore, the anticipation is an optimization problem.

The principle of anticipation is based on predictions such as: weather forecast (wind data, temperature...) and the network demand (power, energy and / or curve of electricity prices), the actual generation capacity of each component (condition, planned maintenance...) ... etc. The anticipation is purely theoretical (no physical control). It permits us to prepare the set values to be applied to each component in the in situ operation. The instructions are determined because they are calculated as a reference in the physical exchange with the network and thus provide an opportunity to address the risks due to uncertainties or vagaries. The calculations are performed using the average values over a time horizon, which is the duration of the operation plan to be determined. Depending on the length of this horizon, the goal may be different. 


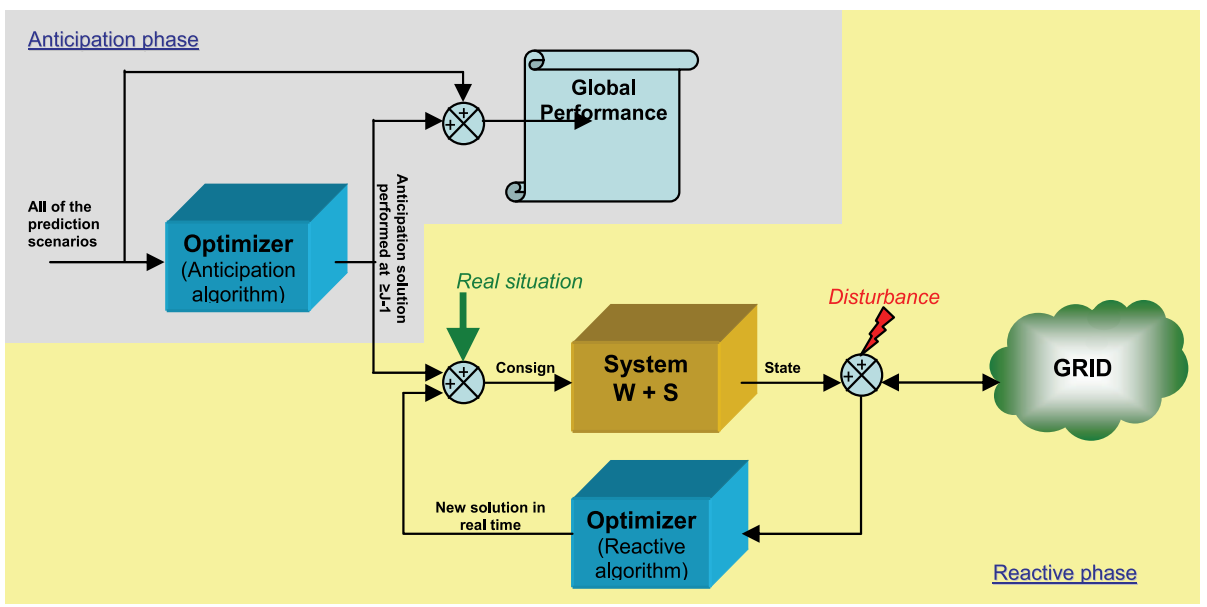

Fig. 8. Architect of the management system

In order to know the operation anticipation of the system $W+S$, we distinguish two levels of anticipation:

- Anticipation of the hydro storage operation: it consists in defining the macro level of the operation plan of the $\mathrm{W}+\mathrm{S}$ system, especially is the use of storage capacity in order to better adapt to wind availability. It seeks to determine the maximum and minimum storage basins at specific times.

The horizon of anticipation to be considered has to suit the storage capacity, the wind power capacity and the quality of forecasts. It is possible to plan the operation rather medium-term (days, weeks, month or season). It can be called the anticipation plan at the horizon of the day ahead D-1. The more storage capacity has, the longer anticipation horizon is. This allows us to anticipate a global view of operations and system performance over time. However, the longer horizon to consider is, the worse forecast is and so we has the risk of predicting values which are averages, shrouded uncertainty. Moreover, by considering the system over a long period, the calculation sample must be carefully chosen because the size and complexity of the optimization problem and the solution time depends on it. Typically, the sample varies from 1:00 to 3:00.

- Anticipation of the exchange between wind energy and the network: whatever the type of centralized power system (vertically integrated) or decentralized (managed by the electricity markets), the anticipation at the day ahead for the next day is an obligation for each participant. The challenge of this step is important because it provides the network manager the information needed to ensure proper coordination between the production and the consumption of system participants. For the $W+S$ system, the anticipation arms to define an operating plan that allows us:

- to propose its best offer of production to maximize the benefit of wind power production;

- to anticipate risks and to predict the operating margin to minimize the impact of the intermittent nature of production and thus limit the these impacts on the network.

The horizon to be considered is therefore 24 hours (from midnight to midnight), also called anticipation on the horizon of the day ahead D-1. Sampling computation depends on that used by the system, typically it is 15, 30 minutes or 1 hour. 
Thanks to optimal computations of operation plan, estimated costs and benefits are calculated. Moreover, beyond a simple prediction of operation, anticipating on the horizon of the day ahead D-1 must be able to "secure" the achievement of the target. The notion of "secure" is indeed to provide in terms of control a certain level of flexibility and tolerance face to the disturbances. This could be achieved by further analysis on sensitivity of obtained solutions in function of input parameters variability.

\section{b. Dynamic and reactive management in real time}

The purpose of the dynamic and reactive pilotage in real time is the intermittent and dynamic characteristic of the system $\mathrm{W}+\mathrm{S}$. Indeed, at first, it is simply to ensure that it functions correctly according to the plan of operation in anticipation. Subsequently, face to the problem appears with the disturbances up to the day ahead, the problem is a proactive and dynamic management, which permits us to found the best compromise to minimize the damage. The consequences of decisions taken at a given time should be reassessed continuously and, if necessary, modified. Then, new actions should be taken. For these reasons, the process is considered reactive management based on two levels:

- Reactive "spontaneous" management: the adjustment is within the capacity of internal regulation of each component of the system (wind, hydroelectric and pump);

- Predictive management at the slipped horizon: it arms to call the optimizer, each time when the difference between the measured value and the prediction value exceeds a certain acceptable threshold (at instant $\mathrm{H}$ in Fig 1), review or redefine the operating plan for the period called the prediction horizon slipped between $\mathrm{H}+1$ and $\mathrm{T}$ (the end of the expected prediction horizon). Following this reassessment in function of new available data the new instructions are recalculated. The illustration of the predictive management process in real time is presented in Fig 12.

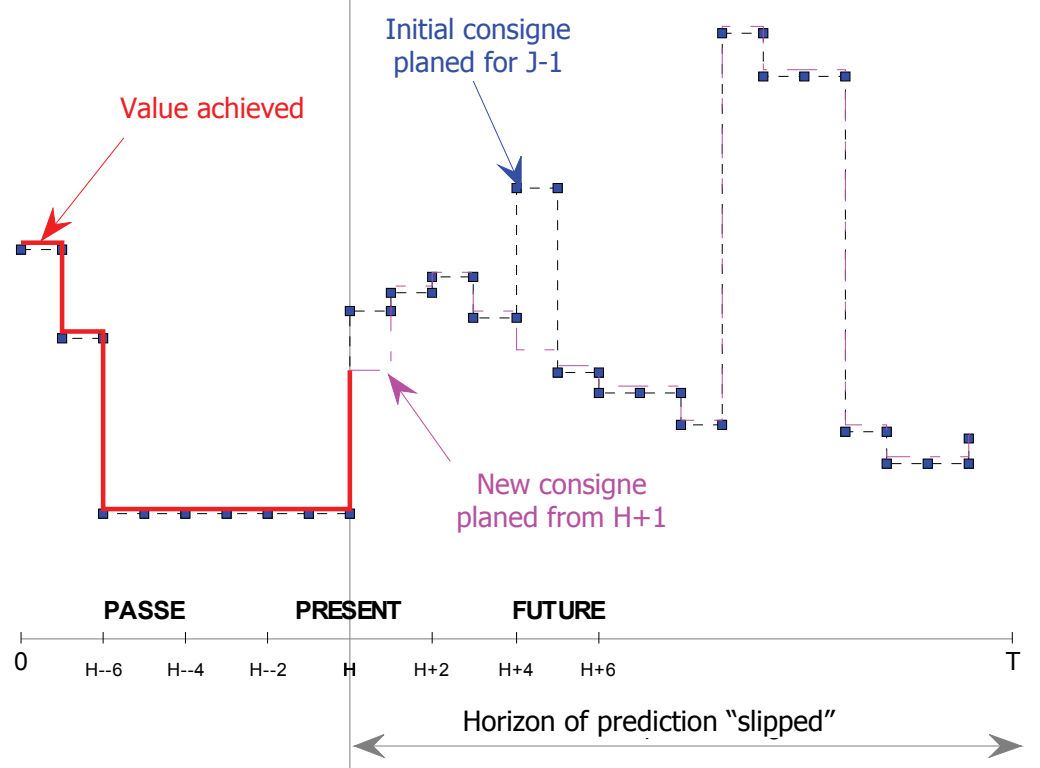

Fig. 9. Nesting time in the reactive management 
In this section, we proposed the architecture of the optimized management system. The following sections are specifically devoted to the optimization module with: the structure of input and output data, the mathematical modeling of the problem and the choice for method resolution.

\subsection{Hypotheses and data structuring}

\section{a. Prediction of wind power}

As already mentioned in the above paragraph, the wind power is a variable and intermittent energy source. To develop a method for managing the wind energy, a good forecast of wind production associated with the estimation of uncertainty is primarily important input data. The purpose of the wind generation prediction is to provide an estimate power generation at a given time in the future. The "peak" prediction is the most common model: for each time step in the future, a single value is provided. The forecast is given in power because it uses the characteristic curve that directly converts the wind speed in power. It is defined by several time horizons:

- a few days a week: this forecast could facilitate the anticipation of the use of storage;

- a few hours in the range from 24 to 72 hours: This prediction is essential for managing the electricity system in general and the wind system in particular. We'll use this prediction for the anticipation of our system operation;

- a few minutes of one hour: it is the very short term forecast - even in real time, which can be used for active control of the turbines.

Naturally, the quality of the prediction increases as the prediction horizon is reduced.

Knowing that the forecast still contains certain of error what is defined as the difference between the measured and estimated (predicted) value, theoretically, several research exist to take into account the uncertainties such as:

- a stochastic model: we assume that these uncertainties are random variables following the probability law;

- interval model: we assume it is possible to determine an interval of plausible values that bound the actual values;

- scenario model: one defines a number of scenarios of possible uncertainties based on the study of histories, trends ...

In this article, we use the combination of two models: intervals and scenarios by determining 3 values for each point of prediction (minimum, average and maximum).

b. Operation of the $W+S$ system in the electrical system

The electrical system in which the $\mathrm{W}+\mathrm{S}$ participates, presents a deregulated organization. The coordination of production and consumption bases on a sequence of two modules at medium action and horizon distinct actions (cf. [SAG-07]).

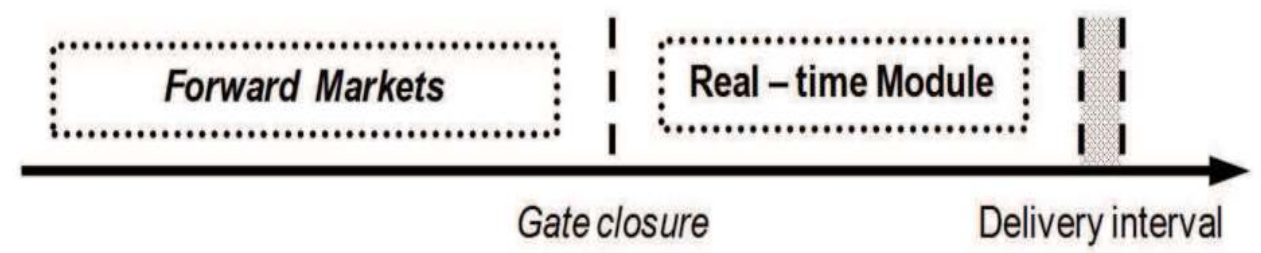

Fig. 10. Principle of the organization of electricity markets 
The first module of electricity markets permits its participants to prepare a decentralized mode and forecast their energy exchanges in real time. These markets, called "forward", are composed of several levels:

- market before the day ahead D-1 arms to prepare long scale trade (week, month, year);

- market of the day ahead D-1 arms to prepare the coordination of production and consumption the next day;

- market of infra hours arms to coordinate the operation for the next few hours, so as to exploit all opportunities to better manage the vagaries.

The participant producers in forward markets respect the following common rule: based on forecasts (weather, consumption...); producers anticipate their operation to identify offer production, i.e. a quantity of energy exchanged with the network for each delivery interval. The choice of the length of this interval depends on the considered system.

This step is purely financial and trade deals are permitted until a time called the gate closure. At the time of gate closure, the market therefore has all the information needed to define, based on production offers and demand loads, the best compromise towards the power demand and the amount of energy to be delivered. This is to minimize the total operating costs while ensuring the safe operation of the system. Thus, the electricity price for each delivery interval is determined.

In France one day is from midnight to midnight, composed of 48 intervals of 30 minutes. The gate closure is $16 \mathrm{pm}$ the previous day for the markets forward. The market of infra hours is 45 minutes before physical delivery. The price used is the weighted average price (PMP: Prix Moyen Pondéré in French).

The second module, in which the actual time starts from the gate closure, performs the centralized coordination of production programs with the overall consumption and the management of physical constraints of the system. Any variation between the proposal at forward markets and the physical delivery will require the network manager to use the necessary actions to ensure system balance. For this reason this module is called an adjustment mechanism. It consists of two stages:

- Stage 1: Set frequency - power (primary and secondary) automatically by the responsible groups of the balance (with a specific contract with the network manager) within a very short time (less than 10 minutes);

- Stage 2: optimization of load distribution and return operating margins. This setting is available through modifying operation demands of the other actors in the system. All producers or consumers are eligible for this adjustment phase.

The adjustment mechanism is expressed by the rule of difference at unique or a double price. In France, the adjustment is at double price, Table 1. This is to encourage favorable ranges and to penalize unfavorable ranges in the system. In the first case, the ranges are generally favorable for PMP defined by the market of the day ahead D-1. In the second case, the unfavorable range is penalized for PMP price revised at a multiplicative factor [SAG-07], [TEN]

For example, at time $t$, the tendency of the network is increasing. It means that the system is in energy deficit. A producer provides an amount of energy:

- either less than the offer made at D-1, that will aggravate the situation. There will be penalized for each $\mathrm{kWh}$ not supplied at a price of: $P M P \cdot(k+1)$;

- or greater than the offer made at D-1, which goes in the right direction to relieve the system. It will be paid for each additional $\mathrm{kWh}$ at a cost of: PMP . 


\begin{tabular}{|c|c|c|c|}
\cline { 2 - 4 } \multicolumn{1}{c|}{} & \multicolumn{3}{c|}{ Trend of adjustment mechanism } \\
\cline { 2 - 4 } \multicolumn{1}{c|}{} & upward & downward & null \\
\hline $\begin{array}{c}\text { Positive } \\
\text { difference }\end{array}$ & $P M P$ & $\frac{P M P}{(k+1)}$ & $P M P$ \\
\hline $\begin{array}{c}\text { Negative } \\
\text { difference }\end{array}$ & $P M P \cdot(k+1)$ & $P M P$ & $P M P$ \\
\hline
\end{tabular}

Note : In France since 2005, $\mathrm{k}=0.12$

Table 1. Price of regulation of ranges in the adjustment mechanism

It is the network manager who will make the selection to offer and activate the change order from the operation program of selected producers.

Thus, in the context of this thesis, we consider that the $W+S$ system works in electricity market following the same rule as other producers as described above. Nevertheless, by its intermittent nature, we assume that the $\mathrm{W}+\mathrm{S}$ system does not intervene at the first stage of the adjustment mechanism. That is to say, it does not offer the reserve primary and secondary frequency.

\section{Problem formulation}

The problem of optimal management of the $W+S$ system described in the preceding paragraphs has all characteristics of an optimization problem where we use limited resources to achieve optimal goals. This can be solved by techniques optimization.

Optimization techniques are algebraic and numerical approaches based on mathematical programming. An optimization technique based on a class of decision variables and arms to prove the existence of a scenario that is the best of all possible scenarios. This scenario is known as optimal solution. Two large families of optimization methods exist:

- $\quad$ exact methods;

- heuristic methods.

Early approaches, such as their name suggests, are accurate and effective. The optimality of obtain results is mathematically proven. However, these methods require knowledge of mathematical programming in order to build adequate and appropriate models. Problem formulation (objective function and constraints) in mathematical form is sometimes laborious especially when the complexity of the problem increases. The cost of calculation time and informatics resources is also a weak point which demotivates to choose these methods if there are problems of very large size. In the area related to resource allocation, linear programming and its extensions such as integer programming or mixed linear programming and dynamic programming are mathematical techniques commonly used for solving such problems.

The latter approaches are methods of solving complex problems and mathematically less robust but based on good significations. They do not guarantee obtaining the optimal solution but a solution whose performance is generally quite good and similar to those of the first approaches, we speak of sub-optimal solutions. These reduced robust approaches can save time and computational cost for complex and large problems.

To address the problem of optimal management of the $W+S$ system, we choose a method belonging to the family of exact methods: linear programming. It is an effective and realistic 
method. It has the advantage of flexibility modeling which allows us easily introduce extensions (including consideration of new variables or constraints).

In addition, the combination of increased computing power with specialized software strides such as the CPLEX solver, the solver JLPK or one integrated in MATLAB (MPT ...) makes a possibility of solving very large linear programs in a reasonable time [MOM-01].

\subsection{Linear Programming (PL)}

The implementation of the linear programming technique can be divided into several stages:

- identifying the problem as being solvable by linear programming. This identification is the contribution of deep knowledge of the physical phenomena and to the mathematical modeling of the problem;

- formulating the problem with using a linear mathematical model (equation formulation of variables, objective function and constraints);

- $\quad$ solving the theoretical problem using techniques algorithmic;

- determining a real solution from the theoretical (mathematical) solution;

- verification and validating the solution.

a. Mathematical model

The term "linear programming (LP) implies that solutions must be found to be represented by real variables. The objective function and constraints are represented in linear form.

When the problem consists of continuous and discrete variables (integer or binary), Linear Programming extends to the Mixed Linear Programming (MLP) or Integer Linear Programming (ILP). In the following, we use the name "PML".

The general expression of the PML is:

$$
\begin{array}{ll}
\text { Minimize: } & F(x) \\
\text { Subject to constraints: } & A \cdot x \leq b \\
& l b \leq x \leq u b
\end{array}
$$

Where:

$x$ : vector of variables (continuous, discrete)

$\mathrm{lb}, \mathrm{ub}$ : lower and upper bounds of $\mathrm{x}$

A, $\mathrm{b}:$ constraint matrices

$\mathrm{F}$ : expression of the objective function

All types of objective functions or constraints can be written in standard form.

For an objective function to maximize:

Maximize $P(x)$ is equivalent to Minimize $-P(x)$

For an equality constraint: $a(x)=b$ is equivalent to $a(x)+\delta \geq b$

$$
-a(x)-\delta \leq-b
$$

with $\delta \geq 0$

For an upper inequality constraint: $a(x) \geq b$ is equivalent to $\quad-a(x) \leq-b$

Example :

Maximize:

$$
P(x)=8 x_{1}+5 x_{2}+6 x_{3}
$$


Constraints:

$$
2 x_{1}+3 x_{2}+2 x_{3} \leq 85
$$

$$
\begin{gathered}
x_{1}+2 x_{2}+1 x_{3} \leq 81 \\
4 x_{1}+3 x_{2}+1 x_{3} \leq 120 \\
x_{i} \geq 0, i=[1 \ldots 3]
\end{gathered}
$$

The presentation of the problem in standard form is as follows:

$$
\text { Minimize: } \quad F(x)=-8 x_{1}-5 x_{2}-6 x_{3}
$$

Therefore, we have:

$$
x=\left[\begin{array}{l}
x_{1} \\
x_{2} \\
x_{3}
\end{array}\right], l b=\left[\begin{array}{l}
0 \\
0 \\
0
\end{array}\right], u b=\left[\begin{array}{l}
+\infty \\
+\infty \\
+\infty
\end{array}\right], F=\left[\begin{array}{l}
-8 \\
-5 \\
-6
\end{array}\right], A=\left[\begin{array}{lll}
2 & 3 & 2 \\
1 & 2 & 1 \\
4 & 3 & 1
\end{array}\right], b=\left[\begin{array}{l}
85 \\
81 \\
120
\end{array}\right]
$$

\section{b. Solution approach}

- Algorithm for solving Linear Programming (PL)

Considering the constraints and limits imposed on the variables, we can determine the trust region. This region collects all the feasible solutions. If we fail to build a region where all constraints are verified, the problem is considered infeasible.

There is a solution in this region, which corresponds to a minimum of the objective function (the problem is presented in its standard form, so the objective function to minimize). This solution is called the optimal solution.

Moreover, it is possible to have one or more optimal solutions that give the same optimum. Many methods have been developed to solve the LP problem whose variables are strictly continuous. The most frequently used techniques are known as the graphical method, simplex method and its variants.

- Graphical method: a feature of the PL is that the optimal solution, if it exists, is one of the highlights point of the "polytope" formed by the constraints and bounds of variables. Therefore, after building the region of feasible solutions, it suffices to inspect the vertices and find the solution that gives the minimum value of the objective function. The illustration of the graphical method is given in Fig. 11.

This method is very illustrative but is difficult to apply to large problems.

- Simplex method: developed by Dantzig in 1947, this method and its variants are widely used in solving the PL. This method based on the matrix approach is much more efficient for computer-assisted calculations.

The idea is to transform inequality constraints into equality constraints by adding slack variables / artificial $\delta$. The problem becomes:

$$
\text { Minimize: } \quad F(x)
$$

Subject to: $\quad A \cdot x \leq b$ which is transformed into $A \cdot x+\delta=b$ 


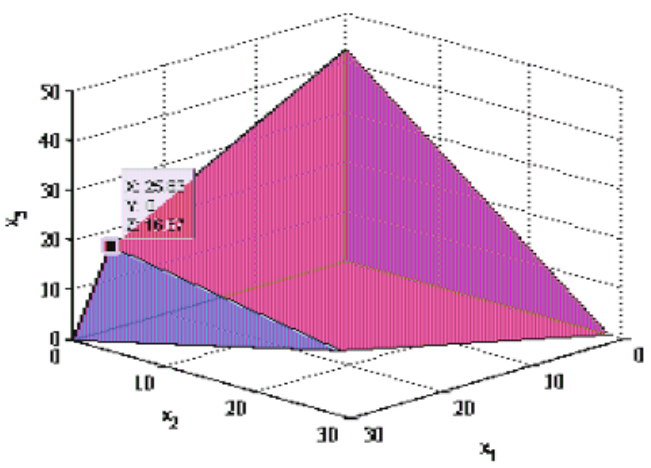

$$
\begin{aligned}
& x=\left[\begin{array}{l}
25.83 \\
5.67 \cdot 10^{-8} \\
16.67
\end{array}\right] \\
& F_{\min }=-306.67 \\
& P_{\max }=306.67
\end{aligned}
$$

Fig. 11. Feasible region and optimal solution of the presented example

- Then, by solving the equation $A \cdot x+\delta=b$ we can obtain some cases:

- $\quad$ no solution : the problem is considered infeasible;

- a unique solution: the optimal solution;

- infinity of solutions forming a feasible region: the region obtained by examining the highlight points in order to find a solution that minimizes the objective function

- $\quad$ Solving Algorithm the Mixed Linear Programming (PML)

By nature of our problem, the variables are of continuous type on one hand and binary decision on the other. The PML problem is a difficult problem. The most common method for this kind of problem is the "Branch and Bound". Its principle is to:

- First, divide the problem into several linear sub problems which are numbered in a logical sequence (separation process) in order to obtain solutions containing only continuous variables;

- Then evaluate each of these sub problems in order to find the optimal solution using the resolution algorithm of the PL (procedure) in making each "tree node";

- $\quad$ Finally, choose the best tree constructed.

In this way, the problem is finding an optimal solution from a combination of NM solutions; with $\mathrm{N}$ being the number of integer variables and $\mathrm{M}$ is the range of values of considered variables.

For the presented example, if we add a constraint considering that all variables are integers, the optimal solution is:

$$
x=\left[\begin{array}{l}
26 \\
0 \\
16
\end{array}\right] \text { and } F_{\min }=-304, P_{\max }=304
$$

\section{c. Sensitivity of the optimal solution to parameter variations}

Once the optimal solution is obtained, we investigate the sensitivity of input parameters. Knowing that the $W+S$ input parameters tainted by uncertainty, analysis of the optimal solution is particularly important goal, which is to propose a management method for $\mathrm{W}+\mathrm{S}$ systems. 
How is the optimal solution if the parameters of the objective function or those relating to constraints vary? In which condition the optimal solution changes or in a worse case where the solution is no longer feasible?

This sensitivity analysis of post-optimization will allow us to answer these questions and to secure the optimal solution to face the intermittent input parameters.

We analyze in this paragraph, two types of uncertainty: first the parameters of the objective function and second the second member of the constraints.

- Uncertainty about the parameters of the objective function $\mathrm{f}_{\mathrm{i}}$

Continuing the example presented in previous paragraphs, we suppose it has an uncertainty on the parameter of the objective function:

$$
F=\left[\begin{array}{l}
-8 \\
-5 \\
-6+\delta
\end{array}\right], \text { with }-\infty \leq \delta \leq+\infty
$$

We can draw its graph based on the coefficient of variation (see Fig. 12)

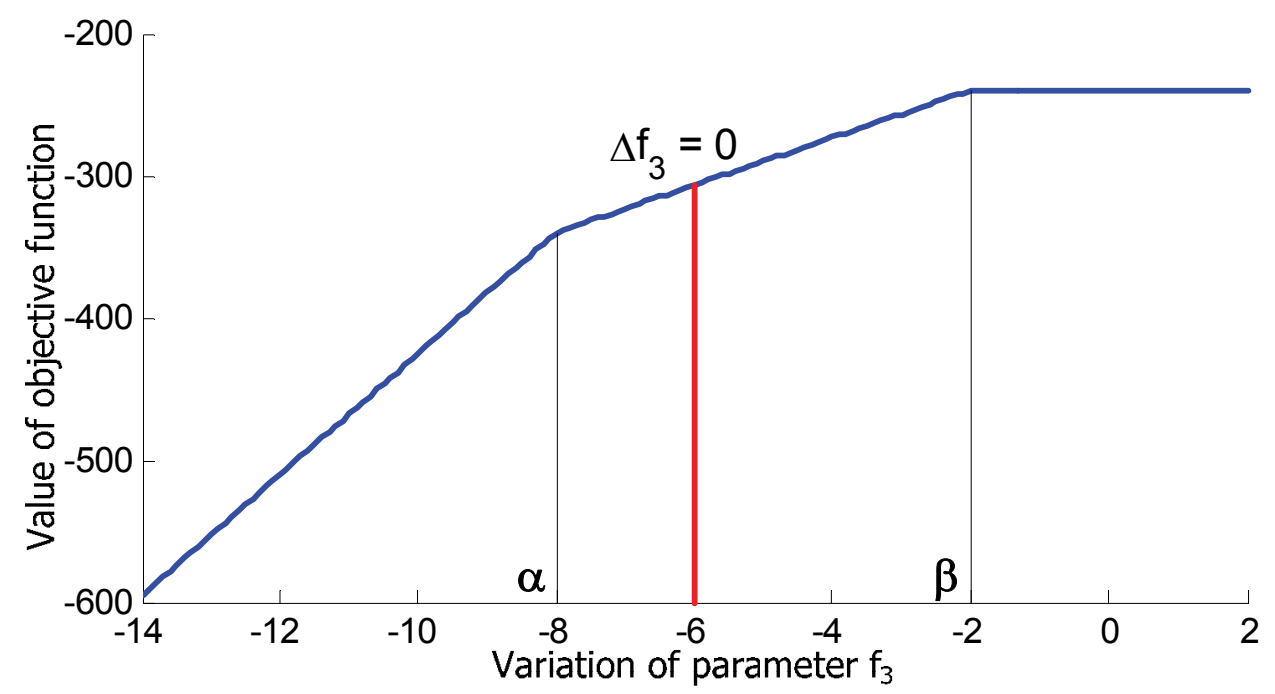

Fig. 12. Sensitivity of the objective function to parameter variation $f_{i}$

With $\delta=0$, the optimal solution is that initially obtained.

It is found that the value of $\delta$ can have two specific values $\alpha$ and $\beta$ :

- With :

$$
f_{3}=-6+\delta \leq \alpha \leftrightarrow \delta \leq \alpha+6
$$

Note that the objective function responds linearly to a linear change of the coefficient $\mathrm{f}$. The more $\delta$ decreases the more objective function decreases, then is minimized, and vice versa. 
- With :

$$
\left\{\begin{array}{l}
f_{3}=-6+\delta \geq \alpha \quad \leftrightarrow \quad \delta \geq \alpha+6 \\
f_{3}=-6+\delta \leq \beta \quad \leftrightarrow \quad \delta \leq \beta+6
\end{array} \rightarrow \alpha+6 \leq \delta \leq \beta+6\right.
$$

The optimal solution is feasible but the value of the objective function only varies flexibly from the change $\delta$.

- With :

$$
f_{3}=-6+\delta \geq \beta \quad \leftrightarrow \quad \delta \geq \beta+6
$$

The variable $x 3$ is too expensive and the optimal solution is no longer feasible. We say that x3 has more influence on the objective function, which becomes "flat" compared to $f_{3}$.

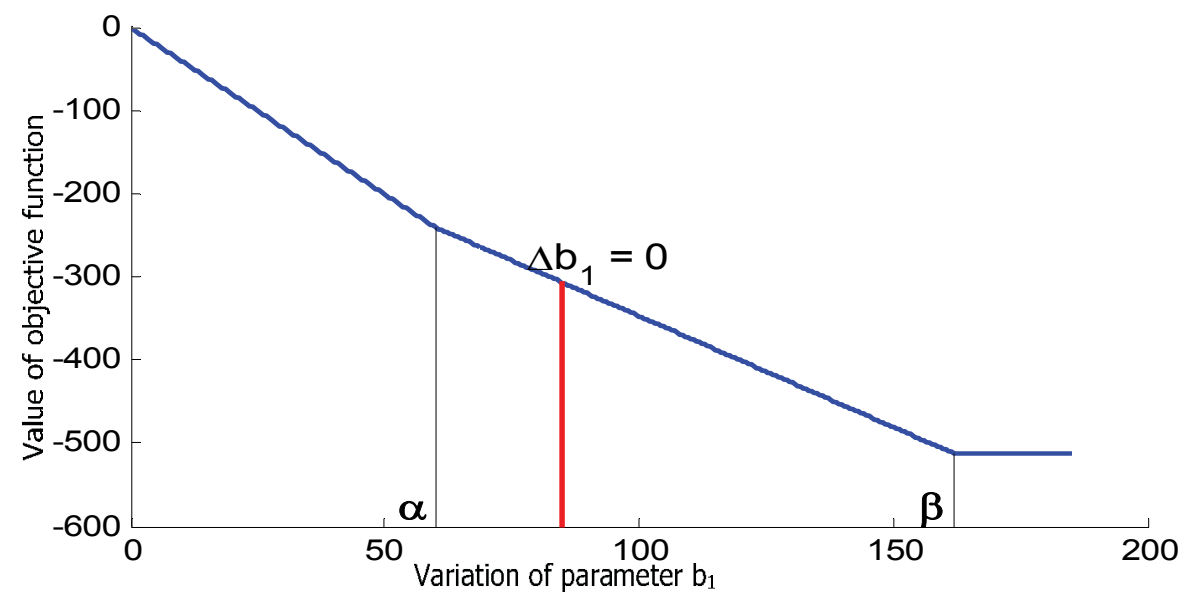

Fig. 13. Sensitivity of the objective function to parameter variation bi

- Uncertainty of the parameters $b_{j}$

We continuing the presented example and suppose it has an uncertainty on the parameter constraint $b_{1}$ :

$$
b=\left[\begin{array}{l}
85+\delta \\
81 \\
120
\end{array}\right] \text { avec }-\infty \leq \delta \leq+\infty
$$

We can draw its graph according to the variation of this coefficient (see Fig. 13).

With $\Delta b_{1}=0$, the optimal solution is that obtained originally.

We see that there are also two specific values of $\delta: \alpha$ and $\beta$

- With :

$$
b_{1}=85+\delta \geq \beta \quad \leftrightarrow \quad \delta \geq \beta-85
$$


The constraint on $b_{1}$ is always satisfied with all $\mathrm{x}$ and $\delta$. It is said that this constraint is unnecessary or redundant. She hasn't influence on both the area of feasible solutions and objective function value.

- With :

$$
\left\{\begin{array}{l}
b_{1}=85+\delta \geq \alpha \quad \leftrightarrow \quad \delta \geq \alpha-85 \\
b_{1}=85+\delta \leq \beta \quad \leftrightarrow \quad \delta \leq \beta-85
\end{array} \rightarrow \alpha-85 \leq \delta \leq \beta-85\right.
$$

The optimal solution is feasible and the value of the objective function varies linearly with the inverse of the variation of $\delta$. The more $\delta$ increases, the more the objective function decreases then is minimized.

- With :

$$
b_{1}=85+\delta \leq \alpha \leftrightarrow \delta \leq \alpha-85
$$

Note that the objective function increases more strongly compared to the previous area because this constrain has become increasingly difficult to verify.

\section{Optimized management of the $\mathrm{W}+\mathrm{S}$ system by PLM}

In this section we describe our problem in mathematic expressions. Firstly we use some

\begin{tabular}{|c|c|}
\hline Glossary & Symbole \\
\hline \multicolumn{2}{|l|}{ System parameters } \\
\hline Optimization period & $T$ \\
\hline Time step & $\Delta t$ \\
\hline Nominal power of wind generator & $P_{w^{n o m}}$ \\
\hline Nominal power of hydroelectric turbine & $P_{\text {hydro }}{ }^{\text {nom }}$ \\
\hline Nominal power of pump system & $P_{\text {pump }}^{\text {nom }}$ \\
\hline Maximal/Minimal power of wind generator & $P_{w^{\max }} / P_{w^{\min }}$ \\
\hline Minimal power of hydroelectric turbine & $P_{\text {hydro }}$ min \\
\hline Minimal power of pump system & $P_{\text {pump }} \min$ \\
\hline $\begin{array}{l}\text { Efficiency of energy accumulation system (hydraulic turbine and water } \\
\text { driving network) }\end{array}$ & 佔ydro \\
\hline $\begin{array}{l}\text { Efficiency of energy accumulation system (pump system and generator } \\
\text { and water driving network) }\end{array}$ & $\eta_{\text {pump }}$ \\
\hline Functioning cost of pump system per kWh & $C_{\text {pump }}$ \\
\hline Maximal capacity of upper/lower storage basins & $S_{\text {sup }}^{\max }, S_{\text {inf }}^{\max }$ \\
\hline Minimal limitation of upper/lower storage basins & $S_{\text {sup }}^{\min }, S_{\text {inf }}^{\min }$ \\
\hline Initial state of of upper/lower storage basins & $S_{\text {sup }}^{\text {init }}, S_{\text {inf }}^{\text {init }}$ \\
\hline $\begin{array}{l}\text { Final state of of upper/lower storage basins at the end of optimization } \\
\text { period }\end{array}$ & $S_{\text {sup }}^{\text {fin }}, S_{\text {inf }}^{\text {finit }}$ \\
\hline
\end{tabular}
nomenclatures. 


\begin{tabular}{|c|c|}
\hline Glossary & Symbole \\
\hline \multicolumn{2}{|l|}{ Signs } \\
\hline Upper sign for variables in anticipation calculation & $a$ \\
\hline Upper sign for anticipation variables in reactive calculation & $r$ \\
\hline \multicolumn{2}{|l|}{ Inputs } \\
\hline Projected power of wind generator & $P_{w}(t)$ \\
\hline Projected electricity cost & $S P_{e}(t)$ \\
\hline Projected cost for power gap & $C_{p}(\mathrm{t})$ \\
\hline Instant of a possible disturbance & $t P$ \\
\hline Real cost for power gap & $P M P(t)$ \\
\hline \multicolumn{2}{|l|}{ Results } \\
\hline Required power for hydraulic turbine & $P_{\text {hydro }}(t)$ \\
\hline Required power for pump system & $P_{\text {pump }}(t)$ \\
\hline Required exchanged power to network & $P_{e}(t)$ \\
\hline Power gap between required and real exchanged power to network & $\Delta P_{e}(t)$ \\
\hline Total benefit during period $\mathrm{T}$ & BT \\
\hline Intern working cost of $\mathrm{W}+\mathrm{S}$ system during period $\mathrm{T}$ & $C T$ \\
\hline
\end{tabular}

Table 2. Parameters and variables used in this section

\subsection{Objective functions}

\section{a. Anticipation of system operation $\mathbf{W}+\mathrm{S}$}

We recall that the anticipation the system $W+S$ aims to maximize the profit from the sale of wind energy. In this way the objective function is expressed by the difference between the sale of energy and the cost of internal work:

$$
F O^{a}=B T-C T=\sum_{t=1}^{T} S P_{e}(t) \cdot P_{e}^{a}(t)-\sum_{t=1}^{T} C_{p u m p}(t) \cdot P_{\text {pump }}^{a}(t)
$$

\section{b. Reactive optimized management}

There is no mathematical optimization to be done to manage "spontaneous" reactive in real time. At the moment where the injection system meets the anticipation plan, the $W+S$ system components work with calculated instructions. Ether wind turbine generator or hydroelectric, if it is functioning, supports the operation in the limit of its capacity.

The problem is complicated with possible disruptions because they can probably change the system state and thus affect the final result. For example with an increase of wind speed, the power injected to the network is more important.

- If this power difference is paid, that is to say that the network trend is upward, it is not necessary to review the operating plan of the $W+S$ because this event enhances the benefit of system.

- On the other side, if the power difference is penalized, that is to say that the trend of the network is downward, would it be wiser to recalculate the level of the $\mathrm{W}+\mathrm{S}$ system in changing the starting or stopping of the hydro-electric generator or theirs of the pumping station to compensate for this loss of profit or simply make better use of the excess energy? 
Here's another example: we suppose the network is lack of power (problem of congestion, defects, consumer vagaries...). So the price of regulation of power deviation is very high, that is to say, each piece of extra supplied energy to the network at that time will be very well paid and each $\mathrm{kWh}$ of shortfall from the expected plan will be much penalized.

- If the system $\mathrm{W}+\mathrm{S}$ is consistent with the anticipatory plan, there will be no impact on the final result.

- Otherwise, using the optimization, the $W+S$ system is able to provide more energy to relieve the network while is maintaining or even is improving the final outcome.

Each time, we call the optimization calculation engine to calculate a new operating plan. This plan covers the period from tP (the appearance of the disturbance) at the end of the anticipation period $(\mathrm{T}=24)$ taking into account new data on the situation following the actual disturbance.

To maximize the overall operation of the system, the objective is to minimize the negative impact of the disturbance according to the best level of function defined in the offer. Thus, the objective function is expressed by an estimate of the penalty due to all $\mathrm{kWh}$ gap to minimize:

$$
F O^{r}=\sum_{t=t P+1}^{T} C_{p}(t) \cdot\left|P_{e}^{r}(t)-P_{e}^{a}(t)\right|
$$

Two remarks are identified by considering l'(4).

- The first is the value of the cost penalty. As the price of regulation of power deviation is only known in real-time, penalty cost introduced by CP values were estimated (based on analysis of historical and current trends of actual network). They are used to better manage the different injected power to the grid.

- The second point concerns the equation formulation of this objective function. An absolute value is considered nonlinear. It requires a mathematical transformation to write the standard form of PML.

By adding a new variable nonnegative $\Delta P_{e}(t)$ :

$$
\Delta P_{e}(t) \geq\left|P_{e}^{r}(t)-P_{e}^{a}(t)\right|
$$

The constraint described in (3) is equivalent to the following two constraints:

$$
\begin{gathered}
P_{e}^{r}(t)-\Delta P_{e}(t) \leq P_{e}^{a}(t) \\
-P_{e}^{r}(t)-\Delta P_{e}(t) \leq P_{e}^{a}(t)
\end{gathered}
$$

The objective function of (2) is written so well in a linear form as following:

$$
F O^{r}=\sum_{t=t P+1}^{T} C_{p}(t) \cdot \Delta P_{e}(t)
$$

\subsection{System constraints}

System constraints $\mathrm{W}+\mathrm{S}$ can be divided into two types: static and dynamic. The first type is in fact specific technical limitations at each component. The second type represents the time 
interdependence of various values during operation. Constraints described below are applicable to the proactive and reactive phase.

\section{a. Static constraints}

The components of the system are supervised by their maximum and minimum.

- Wind turbine:

$$
P_{w}^{\min } \leq P_{w}(t) \leq P_{w}^{\max }
$$

- Hydroelectric generator:

$$
P_{\text {hydro }}^{\min } \leq P_{\text {hydro }}(t) \leq P_{\text {hydro }}^{\max }
$$

- Pumping station:

$$
P_{\text {pompe }}^{\min } \leq P_{\text {pompe }}(t) \leq P_{\text {pompe }}^{\max }
$$

- Basin capacity:

$$
S^{\min } \leq S(t) \leq S^{\max }
$$

- The exchange with the network is considered without technical limitations assuming that the network is sufficiently large to receive the maximum power that can be delivered by the system $\mathrm{W}+\mathrm{S}$.

\section{b. Dynamic constraints}

- $\quad$ The energy produced by the $W+S$ system will be injected to the network.

At any moment we have:

$$
P_{w}(t)+P_{\text {hydro }}(t)-P_{\text {pompe }}(t)-P_{e}(t) \geq 0
$$

- It is preferable not to operate the turbine and pumping in parallel:

$$
P_{\text {hydro }}(t) \cdot P_{\text {pump }}(t)=0
$$

In linear programming, variables are only defined by linear relationships. To get to express this constraint we see the need to introduce a binary decision variable $\alpha(t)$ by referring to [HA-06], so that:

$$
\left\{\begin{array}{l}
P_{\text {hydro }}^{\min } \leq P_{\text {hydro }}(t) \leq \alpha(t) P_{\text {hydro }}^{\max } \\
-P_{\text {pump }}^{\max } \cdot(1-\alpha(t)) \leq-P_{\text {pump }}(t) \leq 0
\end{array}\right.
$$

Demonstration:

$$
\text { Si } \alpha(t)=1 \rightarrow\left\{\begin{array}{l}
P_{\text {hydro }}^{\min } \leq P_{\text {hydro }}(t) \leq P_{\text {hydro }}^{\max } \\
P_{\text {pump }}(t)=0
\end{array}\right.
$$

$\rightarrow$ Only the function of turbine is activated 


$$
\text { Si } \begin{aligned}
\alpha(t)=0 & \rightarrow\left\{\begin{array}{l}
P_{\text {hydro }}(t)=0 \\
-P_{\text {pump }}^{\max } \leq-P_{\text {pump }}(t) \leq 0
\end{array}\right. \\
& \rightarrow\left\{\begin{array}{l}
P_{\text {hydro }}(t)=0 \\
0 \leq P_{\text {pump }}(t) \leq P_{\text {pump }}^{\max }
\end{array}\right.
\end{aligned}
$$

Only the pumping function is activated

- The power supplied by hydro-electric generator at each time step is limited by the available energy stored in the upper basin and the storage capacity of the lower basin:

$$
\frac{P_{\text {hydro }}(t) \cdot \Delta t}{\eta_{\text {hydro }}} \leq \min \left\{\left(S_{\text {sup }}(t)-S_{\text {sup }}^{\min }\right),\left(S_{\text {inf }}^{\max }-S_{\text {inf }}(t)\right)\right\}
$$

- The energy storable in the upper basin at each time step is limited by the available storage capacity of the upper basin and the storage capacity available in the lower basin:

$$
P_{\text {pump }}(t) \cdot \eta_{\text {hpump }} \cdot \Delta t \leq \min \left\{\left(S_{\text {sup }}^{\max }-S_{\text {sup }}(t)\right),\left(S_{\text {inf }}(t)-S_{\text {inf }}^{\min }\right)\right\}
$$

- The stock state of the basin at the beginning and at the end of the day must respect the limits of maximum and minimum filling of the reservoir defined in the macroplan of operation (advance phase of the storage)

$$
\begin{aligned}
& S_{\text {sup }}(t=0)=S_{\text {sup }}^{\text {init }} \\
& S_{\text {sup }}(t=T)=S_{\text {sup }}^{\text {fin }} \\
& S_{\text {inf }}(t=0)=S_{\text {inf }}^{\text {init }} \\
& S_{\text {inf }}(t=T)=S_{\text {inf }}^{\text {fin }}
\end{aligned}
$$

- The temporal evolution of the state of available storage is calculated by examining the input and output powers of the basins:

$$
\begin{gathered}
S_{\text {sup }}(t+1)=S_{\text {sup }}(t)-\frac{P_{\text {hydro }}(t) \cdot \Delta t}{\eta_{\text {hydro }}}+\eta_{\text {pump }} \cdot P_{\text {pump }}(t) \cdot \Delta t \\
S_{\text {inf }}(t+1)=S_{\text {inf }}(t)-\eta_{\text {pump }} \cdot P_{\text {pump }}(t) \cdot \Delta t+\frac{P_{\text {hydro }}(t) \cdot \Delta t}{\eta_{\text {hydro }}}
\end{gathered}
$$

\subsection{Sensitivity of the optimal solution to the data}

For the $\mathrm{W}+\mathrm{S}$ system, the uncertain parameters are: wind power forecasting and stochastic nature of the grid, which are realized as a change in the cost of penalty (the price of 
regulation of power deviation) when there is no correlation between demanded power and supplying power. We will consider changes in the form of a tree of scenarios.

$$
\begin{gathered}
P_{w, S}(t)=P_{w}(t)+\delta_{w}(t) \text { with } \delta_{w \min } \leq \delta_{w}(t) \leq \delta_{w \max } \\
S P_{e}(t)=S P_{e}(t)+\delta_{S P e}(t) \text { with } \delta_{S P e \min } \leq \delta_{S P e}(t) \leq \delta_{S P e \max }
\end{gathered}
$$

\section{Study case}

A representative study case of a wind power plant in Montpellier is chosen. All the parameters for the system sizing problem are recapitulated in the Table 3.

Without loss of generality, it is considered that the two storage basins have the same

\begin{tabular}{|c|c|c|c|}
\hline Parameters & Variable & Value & Unit \\
\hline Nominal power of wind generator & $P_{w^{n o m}}$ & 10 & $(\mathrm{MW})$ \\
\hline Maximal power of wind generator & $P_{w^{\max }}$ & 10 & $(\mathrm{MW})$ \\
\hline Minimal power of wind generator & $P_{w^{\min }}$ & 0 & $(\mathrm{MW})$ \\
\hline Nominal power of hydroelectric turbine & $P_{\text {hydro }}$ nom & 3 & $(\mathrm{MW})$ \\
\hline Nominal power of pump system & $P_{\text {pump }}{ }^{\text {nom }}$ & 3 & $(\mathrm{MW})$ \\
\hline Minimal power of hydroelectric turbine & $P_{\text {hydro }} \min$ & 0 & $(\mathrm{MW})$ \\
\hline Minimal power of pump system & $P_{\text {pump }}{ }_{\text {min }}$ & 0 & $(\mathrm{MW})$ \\
\hline $\begin{array}{l}\text { Efficiency of energy accumulation system } \\
\text { (hydraulic turbine and water driving network) }\end{array}$ & $\eta_{\text {hydro }}$ & 0.8671 & - \\
\hline $\begin{array}{l}\text { Efficiency of energy accumulation system (pump } \\
\text { system and water driving network) }\end{array}$ & $\eta_{\text {pump }}$ & 0.865 & - \\
\hline Storage maximal capacity & $S_{\max }$ & 24 & (MWh) \\
\hline Minimal limitation of storage basin & Smin & 1 & (MWh) \\
\hline
\end{tabular}
capacity.

Table 3. Parameters of $\mathrm{W}+\mathrm{S}$ system

We consider the system of this study case with the same management process as presented in previous sections.

\section{Results and discussion}

\subsection{Anticipation plan of system function at $\mathrm{J}-1$}

a. Anticipation plan of storage use

As mentioned in the section 6, the main objective of the anticipation plan for the storage use is to define a system macro function plan in order to adapt to the wind availability.

An anticipation calculation of the wind speed and the electricity price for the next 7 days is given on the Fig. 14 


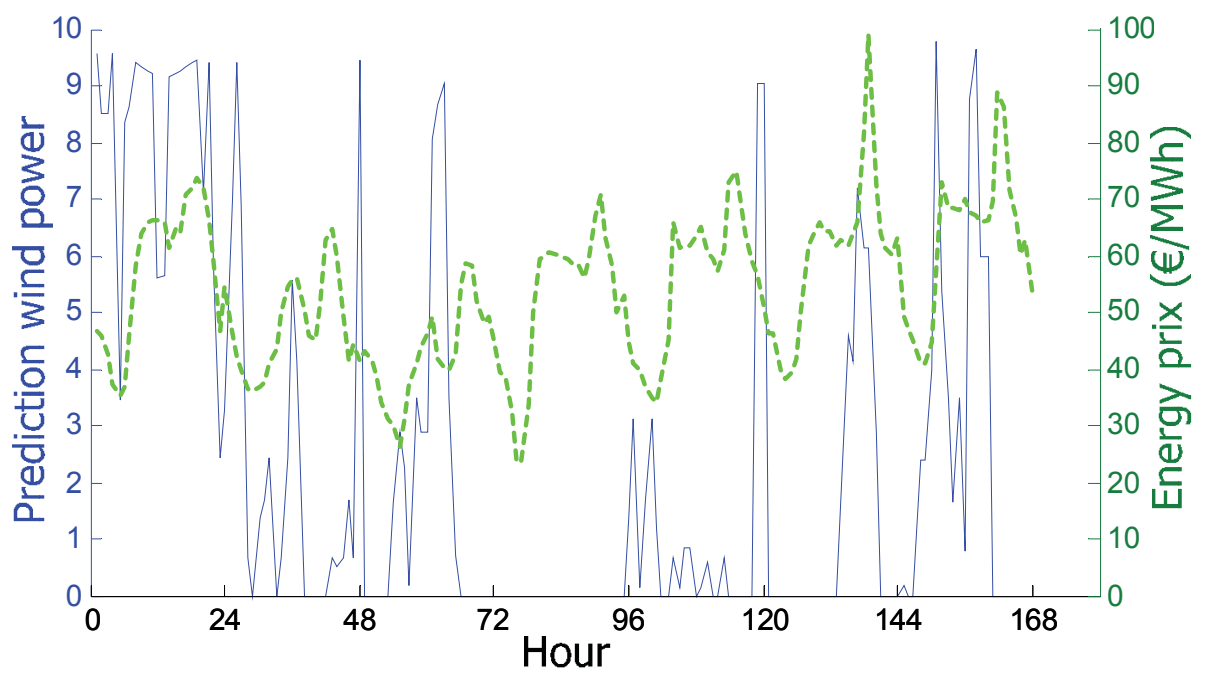

Fig. 14. Forecast date for the next 7 days

It can be observed in this example that a non-homogenous repartition of the wind energy potential capacity during these 7 days, while the electricity price evolution is rather cyclic. The wind potential estimation is summed up in this following table:

\begin{tabular}{|c|c|c|}
\hline Day & $\begin{array}{c}\text { Forecasted produced power } \\
\text { (MWh) }\end{array}$ & Observation \\
\hline 1 & 188.96 & Strong potential \\
\hline 2 & 55.86 & Middle potential \\
\hline 3 & 57.75 & Middle potential \\
\hline 4 & 31.266 & Low potential \\
\hline 5 & 46.27 & Middle potential \\
\hline 6 & 56.46 & Middle potential \\
\hline 7 & 63.876 & \\
\hline
\end{tabular}

Table 4. Forecast wind energy

There are different ways to proceed toward the anticipation plan of the storage use. Two of them will be compared: the first based on " 1 day optimization", the second on "7 days optimization". 


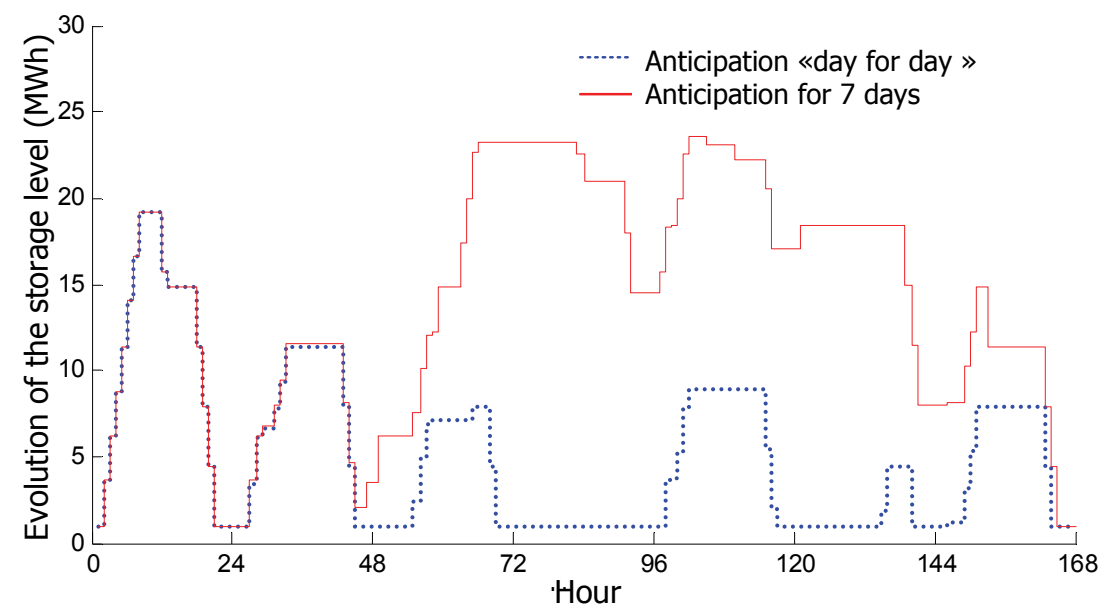

Fig. 15. Different strategies of storage management

We notice clearly two ways to manage the hydroelectric storage. In the first case (illustrated by the dotted line on the Fig. 15), the system management aims to best exploit the storage day by day. In order to optimize economical objective, the system destocks completely at the end of the day. The second case is illustrated by the full-filled line on the Fig. 15. As the objective consist to optimize the system benefit on 7 days period, the system stocks energy during the strong production potential days in order to ensure a better energy development. In both cases, the use rate of the wind energy is maximized: $95.4 \%$ in the first case and $96.3 \%$ in the second. In this example, the longer term optimization (7 days) makes a better use the energy sale to the network. The economical result of the second case is $1.32 \%$ higher than the first.

However, this difference is sensitive to the forecast wind power repartition and to the considered time scale. It is interesting for the $\mathrm{W}+\mathrm{S}$ operator to compare cases in order to find out the best adapted strategy to the wind availability.

b. Anticipation plan of system function at D-1

At D-1, the system has a more precise forecast. This stage is very important as it can help to define energy production offer to the market Day D. In using the data of Day 1 (Fig. 14 and Table 4), the instructions are to be applied to the hydroelectric turbine (Fig. 16, full-filled line) and to the pump system (Fig. 16, dotted line).The energy exchanged with the network at Day D can be forecasted as in Fig. 17

\section{c. Sensitivity to incertitude of anticipation plan}

This exploitation program is the one engaged with the network. It has to be respected in spite of the forecast incertitude and the wind intermittency. In this section, we analyse this program's sensitivity to the wind production variation in order to predict the margin of operation and the actions in disturbance cases. This analysis is carried out based on the sensitivity analyse method previously presented in the section §6.1.c.

We suppose that the precision of the forecast of the average wind speed is $\pm 30 \%$ (cf.Fig. 18). The aim is to manage the system function in such a way that minimizes the power gap between the real exchanged power to the network and the forecasted one. 


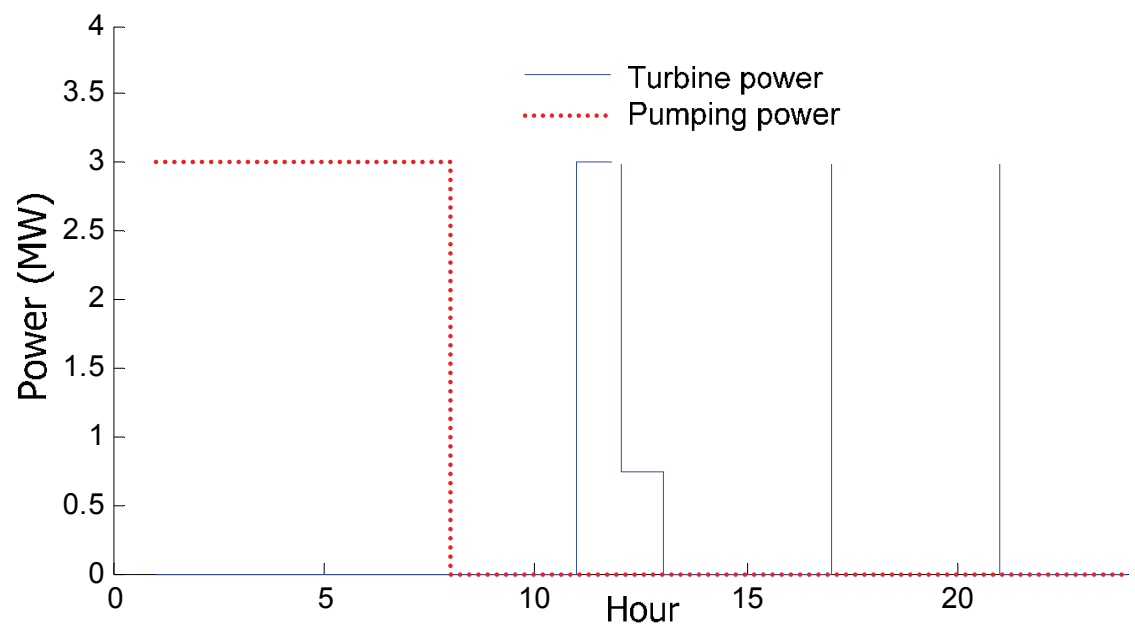

Fig. 16. Power thresholds for hydroelectric turbine and pump Day D

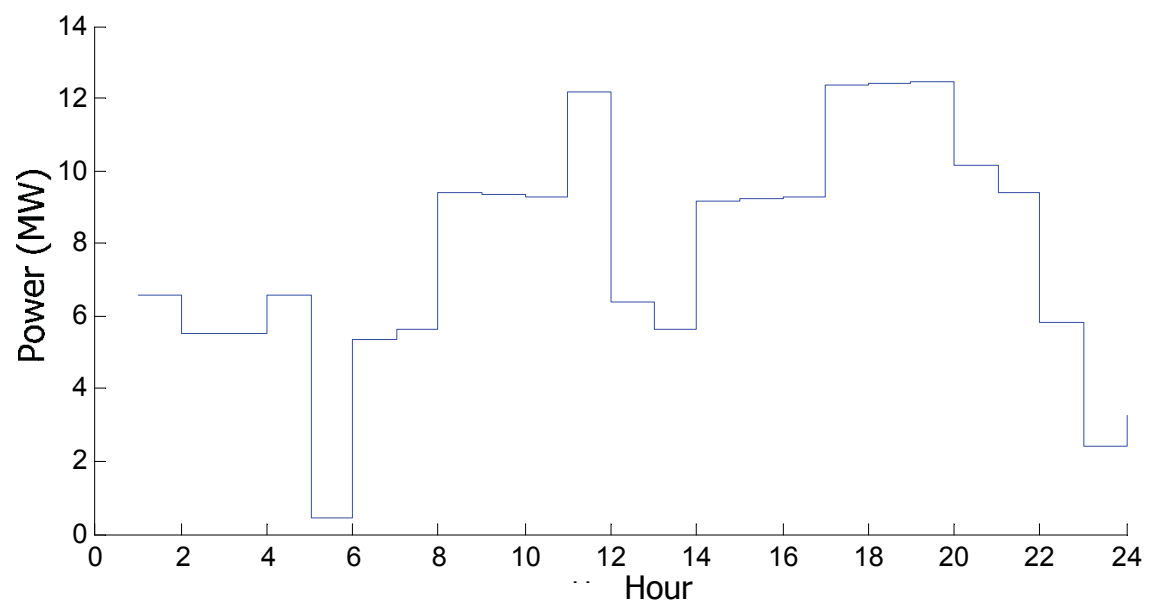

Fig. 17. Forecast of exchanged power to network at Day D 


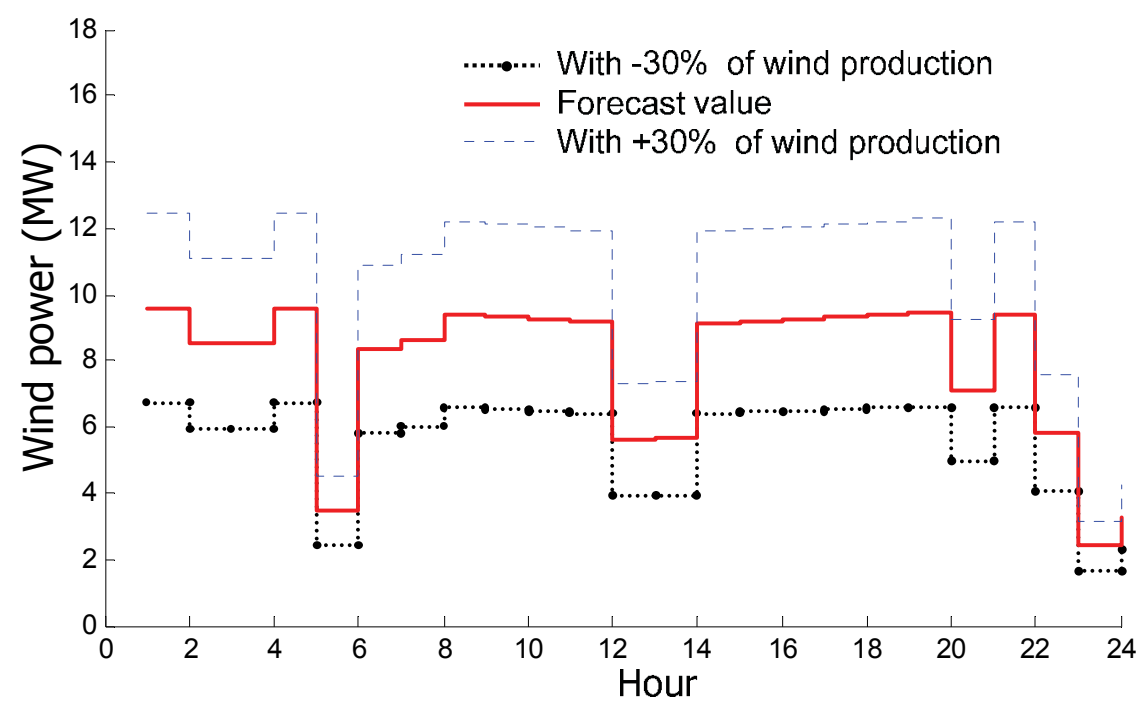

Fig. 18. Scenarios for wind power variation

When the produced wind power is lower than the forecasted one (Fig. 19, dotted line with mark "."), it is recommended to adjust the storage volume and the destocking plan. In order to best reduce the gap between the real and the projected exchanged power, more the wind production tends to decrease, more the storage volume for the day is big.

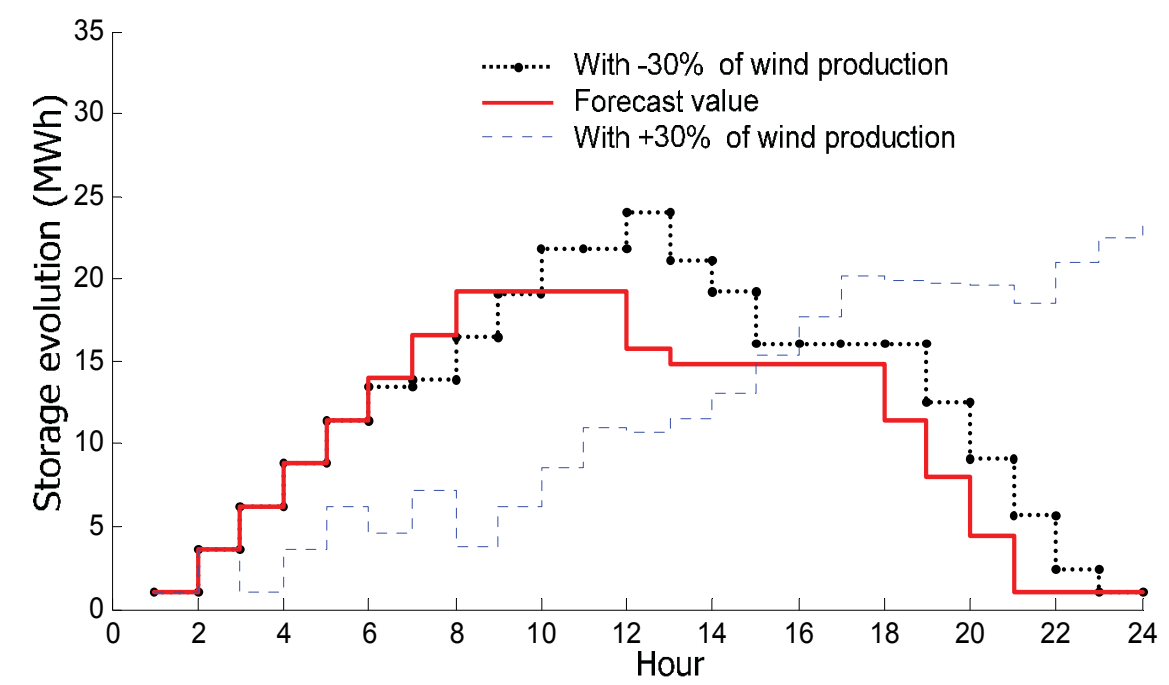

Fig. 19. Storage evolution in relation to produced wind power incertitude 
When the wind production tends to increase, the wind generator can ensure the projected exchange power to the network. Note that the storage need is lower. At the end of the day, the storage level may be not equal to the initially expected level (Fig. 19, dotted line). In this way, the storage use plan for the next days is challenged. It is the responsibility of the wind power manager to decide whether the function plan has to be reviewed. The decision may be made in function of forecast data and the difference between the projected and real storage levels.

The injected power plans of the wind generator to the network are given in the Fig. 20 in 3 cases of wind production scenarios: with initially expected plan (Fig. 20, fulfilled line), with $30 \%$ more than expected (dotted line mark ".") and with $30 \%$ than expected (dotted line). The difference with the initial plan creates penalties.

The objective function's variation is showed in the as the difference between the energy sale benefit (paid by the network) and the penalties. The results are given in percentage compared to the expected power. It is interesting to see that with incertitude of about $\pm 30 \%$ on the wind production, the objective function would vary only about $6 \%$. That proves the interest of the proposed optimal management method.

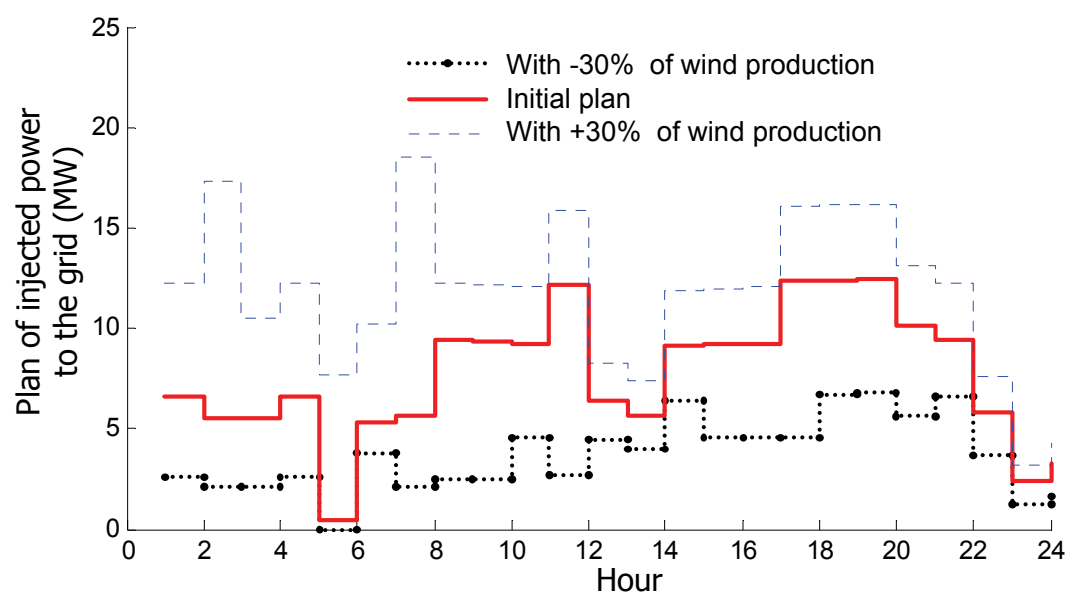

Fig. 20. Plan of injected power to the grid 


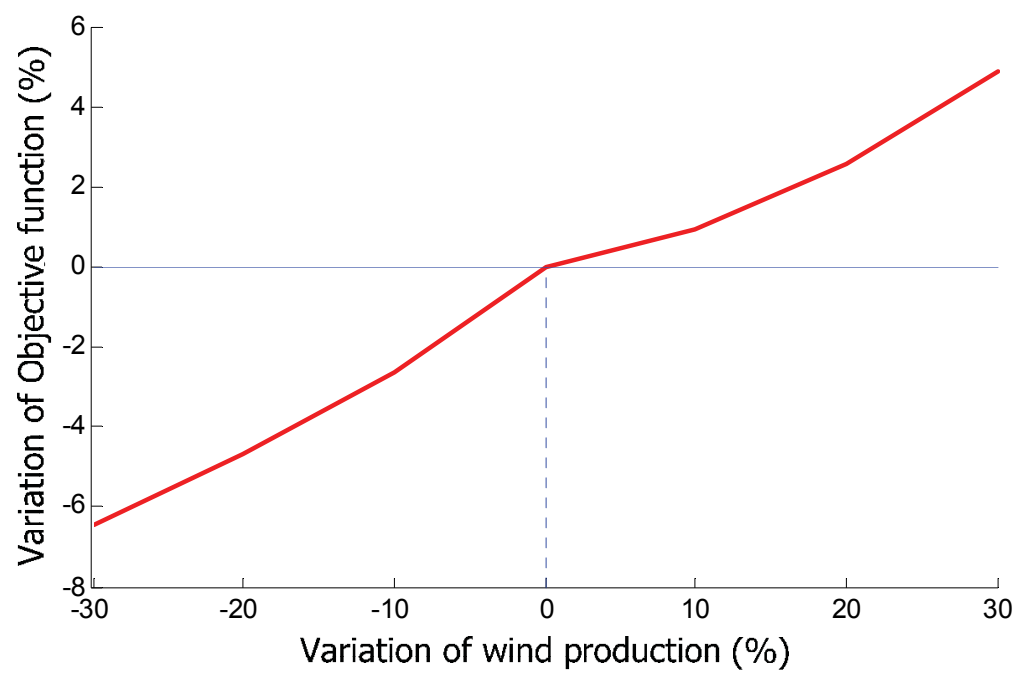

Fig. 21. Objective function's variation in relation to the produced wind power difference (with the expected value)

\subsection{Reactive management in real-time}

We are now J-Day and suppose that some disturbances occur during this day.

- At 5 a.m, a lack of power can be translated by an increasing penalty price for each MW that the W+S system does not provided to the network (from $26.51 € / M W h$ to 76.51 $€ / \mathrm{MWh})$.

- At 10 a.m, the wind production increases from 9.26 MW to $11.26 \mathrm{MW}$.

- At 3 p.m, to response to the network need to reduce injected power, the $W+S$ system has to decrease its provided power from 9.84 MW to 7.84 MW.

The following graphics show the W+S system's behaviour under these conditions and the impact of these disturbances on the global result.

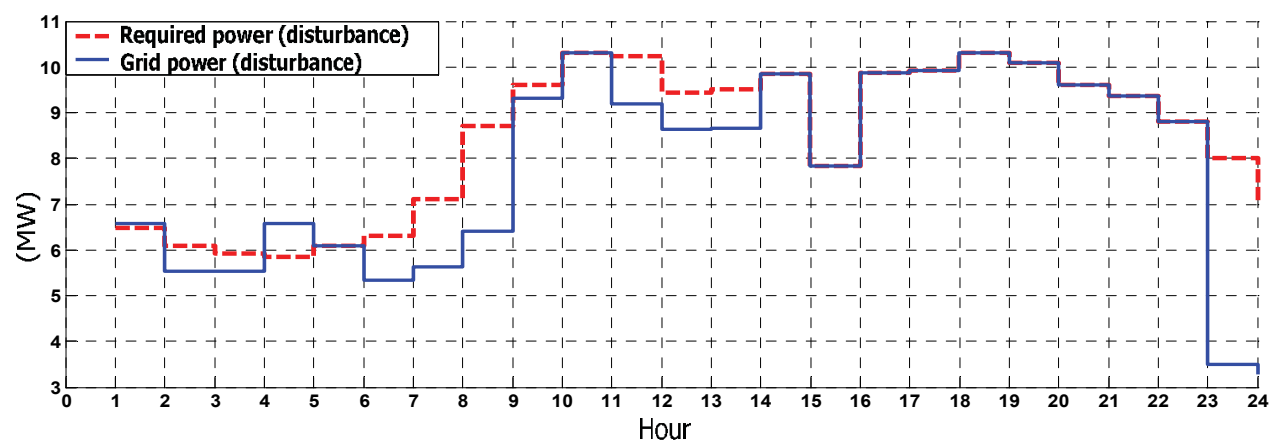

Fig. 22. Final required and exchanged power plan during disturbances 


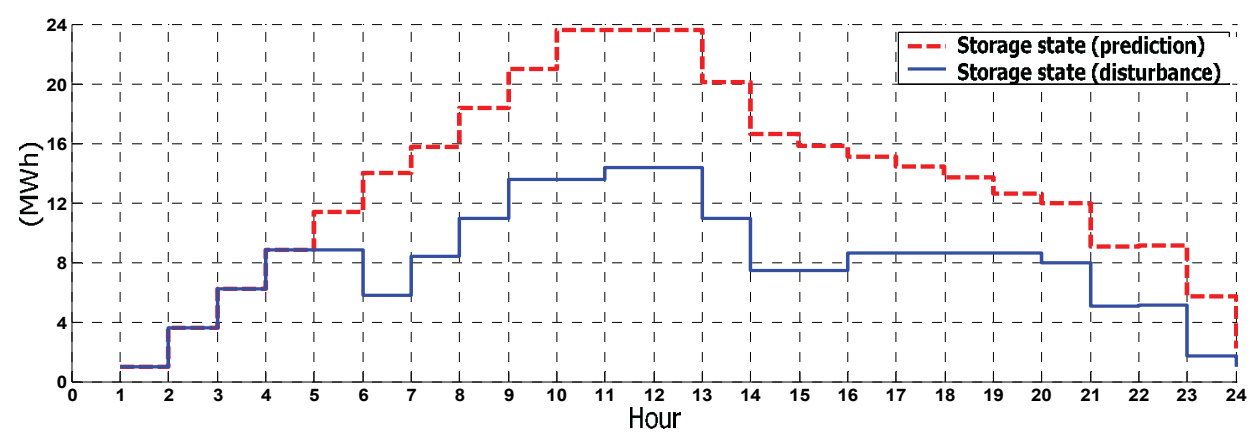

Fig. 23. Evolution of storage state

In order to face these events, new optimal operate plans are computed each time disturbances occurred.

A suitable response is proposed in order to manage several unpredicted events disturbing the system and the electrical network. The optimization response most suits in function of unpredictable constraints occurring. Concretely, the actual total penalty cost is equal to 1020 $€$ per day instead of $2363 €$ per day without disturbances (cf. Table 5).

\begin{tabular}{|c|c|c|}
\hline & $\begin{array}{c}\text { Case I } \\
\text { Maximal economic gains } \\
\text { (in the case forecast - } \\
\text { anticipation) }\end{array}$ & $\begin{array}{c}\text { Case II } \\
\text { Minimal power deviations } \\
\text { (in the case disturbance - } \\
\text { reactive management) }\end{array}$ \\
\hline Total profits [€/day] (1) & 5614 & 5352 \\
\hline Total penalty cost [€/day] (2) & 2363 & 1020 \\
\hline $\begin{array}{c}\text { Total net profit }[€ / \text { day }] \\
(3)=(1)-(2)\end{array}$ & 3251 & 4332 \\
\hline
\end{tabular}

Table 5. Simulations of profit and penalty cost considering two kinds of forecast and disturbances

The benefits of case II is lower than that of case I. But the penalty cost of case II represents only $43.17 \%$ of case I. But the net profit is higher in case II. In conclusion, it is more efficient to manage the reactive management of minimal power gaps is more efficient than the management by anticipation of maximal economic gains.

\section{Conclusions}

The development of an optimized management method of $\mathrm{W}+\mathrm{S}$ systems was the main topic of this chapter. First, a thorough analysis of the W+S system parameters (intermittencies, dynamic, cost efficiency) has been implemented.

Then, bibliography on management methods of $\mathrm{W}+\mathrm{S}$ systems has been carried on. The differences between the methods are mainly due to the applied conditions concerning the wind energy implementation. With support mechanisms, the objective is to maximize the benefits of the wind energy selling to the electrical network. This strategy allowed a 
significant growth of the wind energy during the last years. But, with the increasing of wind energy growth rate a new management method of intermittencies is needed. Its objective is to minimize the impact of intermittencies on the power system.

The purpose of the management method dedicated to the optimal operation of a wind farm coupled to a storage system $(\mathrm{W}+\mathrm{S})$ which has been proposed in this chapter is its adaptation to the specific characteristics of the system in the new context of the wind energy implementation within the electrical network. The optimal management of the W+S exploitation reduces the impacts of intermittencies impacts and better controls the dynamic. Moreover, the economical rentability is preserved. The energy flow optimisation technique allows the supply of a power adapted to the electrical network requirements (network system services). This method is efficient with several disturbance sources such as wind speed intermittency, variable network requirements, penalty cost variability. This system is characterized by the intermittency of the primary source, and by the unpredictable behaviour of the electrical network. The proposed systems of control enable an efficiently operate system management with and without disturbances. In other words, the architecture of the management system is based on two driving levels: anticipative management and real time reactive management. Anticipation is a main step. Operate plan and $\mathrm{W}+\mathrm{S}$ system involvement are determined by anticipation. The mathematic description which has been detailed is based on MLP algorithm which is used for optimisation problem and is seem to be adapted to such problem complexity being highly flexible and fast. Concerning the real time reactive management, its main role is to manage variation and intermittency impacts in real operating time. The optimisation management requires a robust and efficient algorithm. Also, a method of sensitivity analysis has been presented. This analysis gave us a methodological framework to evaluate the impacts of disturbances on the optimal operate system. By this way, the wind energy intermittency is treated on several time scales. Obtained results are based on a feasibility study case. This gives a global view of how operates the system.

\section{References}

[ANA-07] Anagnostopoulos J. S., Dimitris E. Papantonis, "Pumping station design for a pumped-storage wind-hydro power plant", School of Mechanical Engineering, National Technical University of Athens, Heroon Polytechniou 9, 15780 Zografou, Athens, Greece Available online 27 August 2007

[BEN-08] Benitez L. E., Benitez P. C., Cornelis V. K. G., "The Economics of Wind Power with Energy Storage", Energy Economics, Volume 30, Issue 4, July 2008, pp. 1973-1989.

[BUR-01] Burton T., Sharpe D., Jenkins N., Bossanyi E. (2001) “Wind Energy Handbook”, John Wiley \& Sons, Ltd/Inc., Chichester.

[CAS-03] Castronuovo E.D., Peças L. J. A., “Wind and small-hydro generation: An optimisation approach for daily integrated operation", Proceedings of the 2003 EWEC (European Wind Energy Conference). June 16-19, 2003, Madrid, Spain.

[CAS-04a] Castronuovo E.D., Peças L. J. A., "On the optimization of the daily operation of a wind-hydro power plant", IEEE Transactions on Power Systems, Volume 19, Issue 3, Aug. 2004, pp. $1599-1606$ 
[CAS-04b] Castronuovo E.D., Peças L. J. A., “Bounding active power generation of a windhydro power plant", Proceedings of the PMAPS-2004 (8th. International Conference on Probabilistic Methods Applied to Power Systems). September 13-16, 2004, Ames, Iowa, USA.

[CAS-04c] Castronuovo E.D., Peças L. J. A., “Optimal operation and hydro storage sizing of a wind-hydro power plant", International Journal of Electrical Power \& Energy Systems, Volume 26, Issue 10, December 2004, pp. 771-778.

[DWIA] Danish Wind Industry Association, http://guidedtour.windpower.org/fr/tour/ wres/weibull.htm

[EC2007a] EU renewable energy policy, http://www.euractiv.com/en/energy/eurenewable-energy-policy-linksdossier-188269

[EWE-09] European Wind Energy Association, "The Economics of Wind Energy", www.ewea.org, mars 2009

[GAR-06] Gary L. J. (2006), "Wind Energy Systems", Manhattan, KS

[GEN-05] Genc A., Erisoglu M., Pekgor A., Oturanc G., Hepbasli A., Ulgen K., “Estimation of Wind Power Potential Using Weibull Distribution", Energy Sources, Part A: Recovery, Utilization, and Environmental Effects, Volume 27, Issue 9 July 2005, pages 809 822

[GER-02] Gergaud O., "Modélisation énergétique et optimisation économique d'un système de production éolien et photovoltaïque couplé au réseau et associé à un accumulateur", Thèse de doctorat de l'Ecole Normale Supérieure de Cachan, Décembre 2002.

[HAL-01] Halldorsson K., Stenzel J. "A scheduling strategy for a renewable power marketer", Power Tech Proceedings, 2001 IEEE Porto Volume 1, 10-13 Sept. 2001, vol.1, pp. 6 pages.

[KAL-07] Kaldellis J.K., Zafirakis D.,"Optimum energy storage techniques for the improvement of renewable energy sources-based electricity generation economic efficiency", Energy Volume 32, Issue 12, December 2007, Pages 2295-2305

[MAG-03] Magnus K., Holen A. T., Hildrum R., “Operation and sizing of energy storage for wind power plants in a market system", International Journal of Electrical Power \& Energy Systems, vol. 25, Issue 8, October 2003, pp. 599-606.

[MOM-01] Momoh J. A., "Electric Power System Applications of Optimization", CRC Press; 1 edition (January 15, 2001), 478 pages

[NGU-09] Nguyen Ngoc P.D., Pham T.T.H; Bacha S., Roye D. “Optimal operation for a windhydro power plant to participate to ancillary services", Industrial Technology, 2009. ICIT 2009. IEEE International Conference on Digital Object Identifier: 10.1109/ICIT.2009.4939699, Publication Year: 2009, pp. 5 pages

[RTE] Réseau de Transport d'Électricité, http://clients.rte-france.com/

[RTE-08] RTE2008: http://www.rte-france.com/fr/nous-connaitre/espace-esse/dossiers de-presse/le-bilan-electrique-francais - 2008

[SAG-07] Saguan M., “L'analyse economique des architectures de marches electrique. Application au market design du "temps reel", Thèse de Doctorat de l' Université Paris-Sud 11, Avril 2007. 
[SOM-03] Somaraki M., "A Feasibility Study of a Combined Wind - Hydro Power Station in Greece", a thesis submitted for the degree of Master in Science in "Energy Systems and the Environment", University of Strathclyde, Department of Mechanical Engineering, October 2003 - Glasgow 


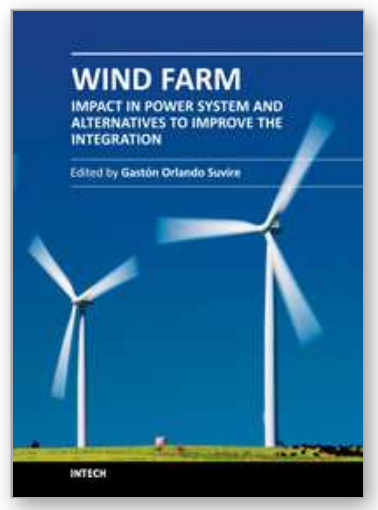

\author{
Wind Farm - Impact in Power System and Alternatives to Improve \\ the Integration \\ Edited by Dr. Gast $\tilde{A}^{3} n$ Orlando Suvire
}

ISBN 978-953-307-467-2

Hard cover, 330 pages

Publisher InTech

Published online 28, July, 2011

Published in print edition July, 2011

During the last two decades, increase in electricity demand and environmental concern resulted in fast growth of power production from renewable sources. Wind power is one of the most efficient alternatives. Due to rapid development of wind turbine technology and increasing size of wind farms, wind power plays a significant part in the power production in some countries. However, fundamental differences exist between conventional thermal, hydro, and nuclear generation and wind power, such as different generation systems and the difficulty in controlling the primary movement of a wind turbine, due to the wind and its random fluctuations. These differences are reflected in the specific interaction of wind turbines with the power system. This book addresses a wide variety of issues regarding the integration of wind farms in power systems. The book contains 14 chapters divided into three parts. The first part outlines aspects related to the impact of the wind power generation on the electric system. In the second part, alternatives to mitigate problems of the wind farm integration are presented. Finally, the third part covers issues of modeling and simulation of wind power system.

\title{
How to reference
}

In order to correctly reference this scholarly work, feel free to copy and paste the following:

Phuc Diem Nguyen Ngoc, Thi Thu Ha Pham, Seddik Bacha and Daniel Roye (2011). Optimal Management of Wind Intermittency in Constrained Electrical Network, Wind Farm - Impact in Power System and Alternatives to Improve the Integration, Dr. Gast $\tilde{A}^{3} n$ Orlando Suvire (Ed.), ISBN: 978-953-307-467-2, InTech, Available from: http://www.intechopen.com/books/wind-farm-impact-in-power-system-and-alternatives-to-improve-theintegration/optimal-management-of-wind-intermittency-in-constrained-electrical-network

\section{INTECH}

open science | open minds

\author{
InTech Europe \\ University Campus STeP Ri \\ Slavka Krautzeka 83/A \\ 51000 Rijeka, Croatia \\ Phone: +385 (51) 770447 \\ Fax: +385 (51) 686166 \\ www.intechopen.com
}

\author{
InTech China \\ Unit 405, Office Block, Hotel Equatorial Shanghai \\ No.65, Yan An Road (West), Shanghai, 200040, China \\ 中国上海市延安西路65号上海国际贵都大饭店办公楼 405 单元 \\ Phone: +86-21-62489820 \\ Fax: +86-21-62489821
}


(C) 2011 The Author(s). Licensee IntechOpen. This chapter is distributed under the terms of the Creative Commons Attribution-NonCommercialShareAlike-3.0 License, which permits use, distribution and reproduction for non-commercial purposes, provided the original is properly cited and derivative works building on this content are distributed under the same license. 